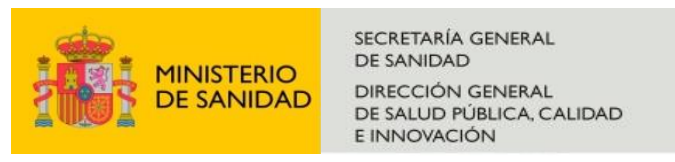

\title{
Guía de cribado de la infección por el VHC
}


Índice

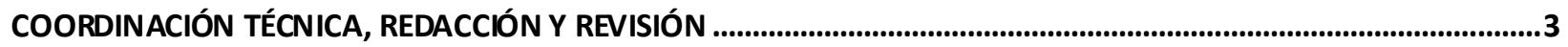

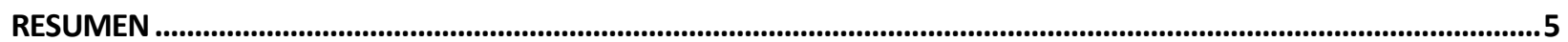

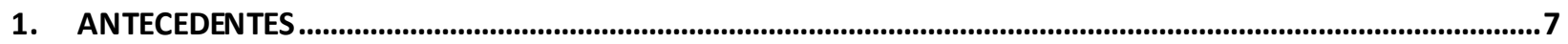

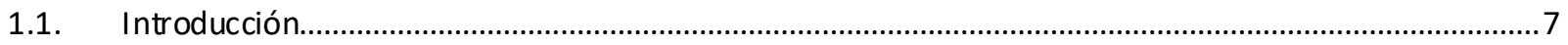

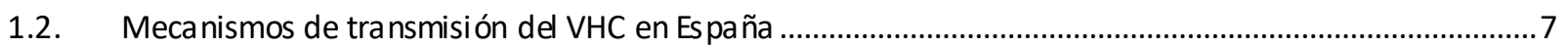

1.3. Situación epidemiológica y diagnós tico de infección por hepatitis $C$ en Es paña .......................................9

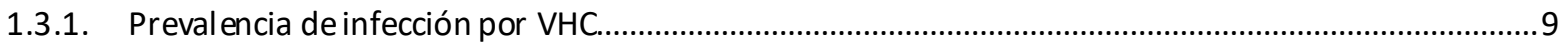

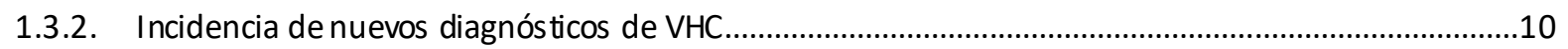

1.3.3. Diagnóstico de infección por el VHCy vinculación al tratami ento ........................................................11

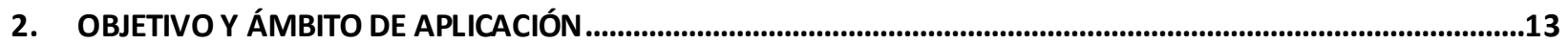

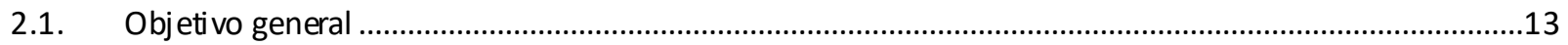

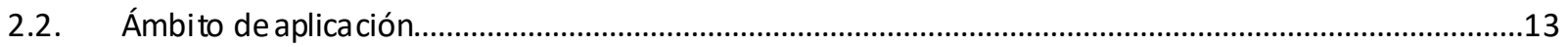

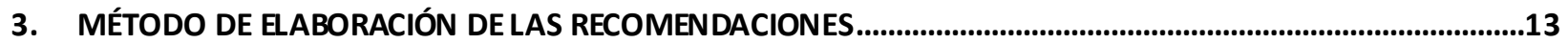

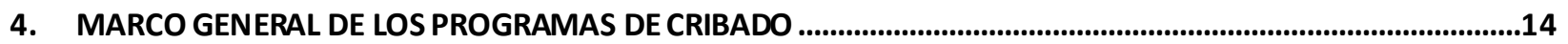

5. PRINCIPIOS BÁSICOS DELA REALIZACIÓN DE LA PRUEBA DE VHC ...................................................................15

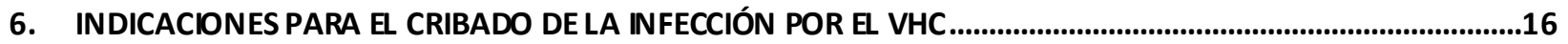

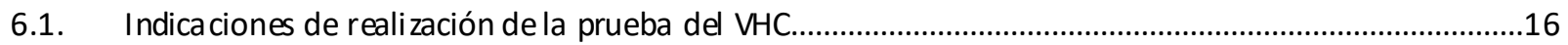

6.1.1. Pers onas con criterios clínicos compatibles con infección por el VHC ..................................................16

6.1.2. Pers onas sin signos ni síntomas de infección por VHC ....................................................................16

6.2. Técnicas de labora torio para el diagnóstico y diagnós tico en un solo paso ...............................................18

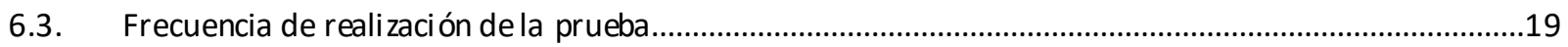

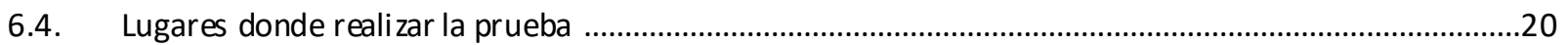

7. RECOMENDACIONES PARAMEJORAR EL ACCESO ALCRIBADO Y VINCULACÓN DE LAS PERSONAS

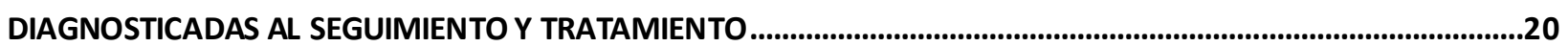

7.1. Actividades formativas y de apoyo a profesionales sani ta rias/os .............................................................20

7.2. Actividades de promoción del cribado dirigidas a población general y poblaciones es pecíficas................21

7.3. Búsqueda e identificación activa de pers onas con necesidad de vinculación al seguimiento y tra tamiento

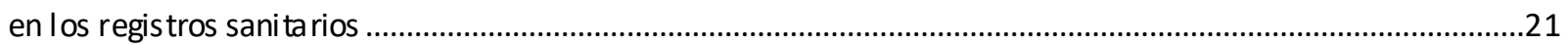

7.4. Si mplificación de la atención e integración de las actividades relacionadas con otras patologías

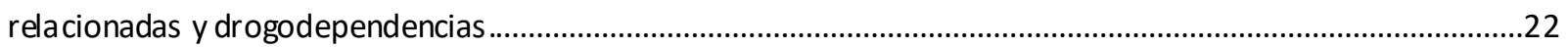

7.5. Coordinación de los servicios de salud e Instituciones Penitenciarias para la continuidad asistencial.....22

8. ENFOQUE DE EQUIDAD EN LOS PROGRAMAS DE CRIBADO DEL VHC ..................................................................22

9. EVALUACIÓN DE LAS RECOMENDACIONES...............................................................................................................23

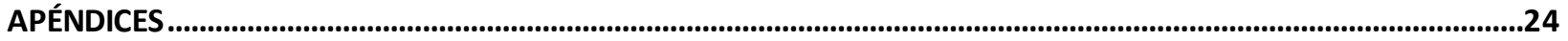

Apéndice 1. Pa ís es con prevalencia media oal ta de anticuerpos anti -VHC ......................................................24 Apéndice 2. Ejemplos de intervenciones rea lizadas en Es paña en relación al cribado del VHC y vinculación de las pers onas diagnosticadas al segui mi ento y trata mi ento ............................................................................................25

BIBLIOGRAFÍA..............................................................................................................................................................................33 


\title{
COORDINACIÓN TÉCNICA, REDACCIÓN Y REVISIÓN
}

\author{
Dirección General de Salud Pública, Calidad e Innovación \\ Pilar Aparicio Azcárraga Directora General de Salud Pública, Calidad e Innovación
}

\begin{abstract}
Secretaría del Plan Nacional sobre el SIDA
Julia del Amo Valero

Raquel González Rubio

Rosa Polo Rodríguez

María Vázquez Torres

Javier Gómez Castellá

Marta Cobos Briz

Lyliam Roxana Tuesta Reina

Magdalena Holgado Pérez

Secretaría del Plan Nacional sobre el Sida

Secretaría del Plan Nacional sobre el Sida

Secretaría del Plan Nacional sobre el Sida

Secretaría del Plan Nacional sobre el Sida

Secretaría del Plan Nacional sobre el Sida

Secretaría del Plan Nacional sobre el Sida

Secretaría del Plan Nacional sobre el Sida

Secretaría del Plan Nacional sobre el Sida
\end{abstract}

Unidad de Programas de Cribado

María Vicenta Labrador Cañadas
Unidad de Programas de Cribado

\section{Grupo técnico de cribado de la infección por el VHC \\ Isabel Pineros Andrés \\ Marta Molina Olivas \\ Enrique Acín García \\ Asunción Díaz Franco \\ Agustín Albillos Martínez \\ María Buti Ferret \\ Javier Crespo García \\ Joan Colom i Farran \\ Xavier Majó i Roca \\ Sara Santos Sanz \\ Rosa Ramírez Fernández \\ Ana Mạ García Fulgueiras \\ Olga Monteagudo Piqueras \\ María Bestué Cardiel \\ Jesús Castilla Catalán \\ Carmen María Lama Herrera \\ Antonio Arraiza Armendariz \\ Eduardo García-Ramos Alonso \\ Subdirección General de Calidad de Medicamentos y Productos Sanitarios \\ Delegación del Gobierno para el Plan Nacional sobre Drogas \\ Subdirección General de Coordinación de Sanidad Penitenciaria \\ Centro Nacional de Epidemiología, Instituto de Salud Carlos III H.U. Ramón y Cajal, Comité Científico Asesor del PEAHC. H.G.U. Vall d'Hebrón, Comité Científico Asesor del PEAHC. H.U. Marqués de Valdecilla, Comité Científico Asesor del PEAHC. \\ Programa de Prevención, Control i Atención al VIH, las ITSylas Hepatitis Víricas \\ Programa de Prevención, Control i Atención al VIH, las ITS y las Hepatitis Víricas \\ Subdirección General de Promoción, Prevención y Educación para la Salud de la Comunidad de Madrid \\ Subdirección General de Promoción, Prevención y Educación para la Salud de la Comunidad de Madrid \\ Servicio de Epidemiología de la Región de Murcia \\ Servicio de Promoción y Educación para la Salud de la Región de Murcia \\ Dirección General de Asistencia Sanitaria de Aragón Instituto de Salud Pública y Laboral de Navarra \\ Subdirección de Planificación, Derechos y Resultados en Salud de Andalucía \\ Dirección de Asistencia Sanitaria del País Vasco \\ Dirección General de Salud Pública de Canarias}




\author{
Pedro Redondo Cardeña \\ Javier García Samaniego \\ Federico García García \\ Conrado Fernández Rodríguez \\ Juan Berenguer Berenguer \\ Miguel Ángel von Wichmann \\ José María Molero García \\ Fernando Pérez Escanilla \\ Manuel Linares Rufo \\ Adolfo García Ortega \\ Damián Caballero Martínez \\ Ramón Espacio \\ Reyes Velayos Corrales \\ Jesús Fargas Prieto \\ Juanse Hernández Fernández

\section{Colaboraciones}

Elena Moro Domingo
Montserrat García Gómez
Yolanda Agra Varela
Cinta Folch Toda
Inmaculada Jarrín Vera
Nieves Martín Sobrino
Guillermina Barril Cuadrado
Fernando Arenas Escribano
Eduardo Muela Pavón

\section{Revisores externos} \\ Marcelo Naveira \\ Antons Mozalevskis \\ Jeffrey V Lazarus
}

Servicio de Promoción de la Salud de la Dirección General de Salud Pública, Junta de Castilla y León

Alianza para la Eliminación de las Hepatitis Víricas en España SEIMC-GEHEP

AEEH

GeSIDA

SEISIDA

SEMFYC

SEMG

SEMERGEN

PLAFHC Madrid

PLAFHC

CESIDA

Apoyo Positivo

FNETH

GTt-VIH

Área de Hemoterapia, Subdirección General de Promoción de la Salud y Vigilancia en Salud Pública

Área de Salud Laboral, Subdirección General de Sanidad Ambiental y Salud Laboral

Área de Seguridad del Paciente, Subdirección General de Calidad e Innovación

Centre d'Estudis Epidemiològics sobre les ITS i Sida de Catalunya

Unidad de Coordinación de la cohorte CoRIS, Centro Nacional de Epidemiología, Instituto de Salud Carlos III

Dirección General de Sistemas de Información, Calidad y Prestación Farmacéutica de Castilla y León

Grupo de Virus en Diálisis, Sociedad Española de Nefrología

Abogacía del Estado del Ministerio de Sanidad

Servicio de Asuntos Jurídicos del Ministerio de Sanidad

\section{Oficina Regional de OMS para Europa}

Oficina Regional de OMS para Europa

Instituto de Salud Global Barcelona (ISGlobal), Hospital Clinic, Universidad de Barcelona 


\section{RESUMEN}

La presente guía recoge las indicaciones del Ministerio de Sanidad sobre el cribado de la infección por el virus de la hepatitis $\mathrm{C}(\mathrm{VHC})$ y la vinculación de las personas diagnosticadas al seguimiento y tratamiento en España, en el marco del Plan Estratégico para el Abordaje de la hepatitis C en el Sistema Nacional de Salud.

El estudio de prevalencia de infección por el VHC realizado entre 2017 y 2018 en España describió una prevalencia de anticuerpos frente al VHC del 0,85\% (IC 95\%: 0,64\%-1,08\%) y de infección activa del 0,22\% (IC 95\%: 0,12\%-0,32\%) en la población de 20 a 80 años. Un 29,4\% de las personas con infección activa no se había diagnosticado previamente. Por lo tanto, se puede calcular que unas 76.457 personas en la población general tendrían infección activa en España, de las que 22.478 no estarían diagnosticadas.

Más del $80 \%$ de las personas con infección por el VHC refieren antecedentes de exposiciones de riesgo para la transmisión del VHC conocidas. En el estudio de prevalencia se identificó un patrón por sexo y año de nacimiento, encontrándose una prevalencia superior en hombres nacidos entre 1948 y 1967, relacionada con la epidemia de inyección de drogas y la transmisión relacionada con la asistencia sanitaria en el pasado. La prevalencia continúa siendo muy elevada en personas que consumen drogas inyectadas, y destaca un aumento de la incidencia y la reinfección por el VHC en hombres que tienen sexo con hombres y que tienen infección por el VIH asociada a la práctica de "chemsex". En algunas de las poblaciones más vulnerables se ha observado una tendencia descendente, como en las personas con VIH, población interna en centros penitenciarios o pacientes en tratamiento crónico con hemodiálisis, si bien sigue observándose una prevalencia superior que en población general.

En base a esta evidencia, las indicaciones para la realización de la prueba del VHC son las siguientes:

- Personas con criterios clínicos compatibles con infección por el VHC.

- Realización obligatoria en los centros de transfusión para la donación de sangre, células y tejidos (incluidas células reproductoras) y de trasplante de órganos.

- Personas con las siguientes exposiciones o situaciones de riesgo para la transmisión del VHC:

- Consumo de drogas por vía inyectada y/o inhalada.

- Relación sexual de riesgo (prácticas sexuales con riesgo de sangrado como el fisting; chemsex; presencia de ITS con ulceraciones genitales o proctitis).

- Pareja sexual con infección activa por el VHC o con consumo activo de drogas inyectadas

- Co-infección por el VIH y/o VHB.

- Tatuajes y/o procedimientos estéticos y similares realizados con instrumental punzante sin las debidas precauciones de seguridad.

- Exposición laboral al VHC.

- Ingreso en unidades de hemodiálisis crónica.

- Intervenciones sanitarias invasivas realizadas en lugares sin las medidas de seguridad adecuadas, como intervenciones quirúrgicas con material no esterilizado antes de 1975 o la recepción de productos sanguíneos o hemoderivados antes de 1990.

- Recién nacido/as de madres con infección por el VHC.

- Ingreso en centros penitenciarios. 
- Procedencia de países con prevalencia de infección por el VHC media o alta (ver apéndice 1 con el listado de países).

No se recomienda el cribado de la infección por el VHC en personas sin exposiciones de riesgo, en base a la evidencia disponible. Esta indicación será revisada en base a nuevos datos epidemiológicos y al informe solicitado a la Red de Agencias de Evaluación de Tecnologías Sanitarias y Prestaciones del SNS acerca de la evidencia de la eficacia clínica y del coste efectividad del cribado poblacional de esta enfermedad.

Por otro lado, se han descrito diferentes barreras generales para el acceso de la población al cribado y a la vinculación al seguimiento y tratamiento de la infección por el VHC. Es necesario identificar las barreras y facilitadores de acceso y uso de los servicios en cada contexto, adecuando la atención sanitaria a las diversas necesidades de las personas y garantizando su universalidad.

Para mejorar el acceso al cribado y la vinculación al seguimiento se proponen las siguientes acciones:

- Diagnóstico de la infección en un solo paso: confirmación de un resultado positivo en una primera serología con una determinación de viremia en la misma muestra.

- Búsqueda de personas que tienen una prueba de anticuerpos frente al VHC positiva en algún registro sanitario sin constatación de confirmación del diagnóstico, así como de personas con diagnóstico de viremia confirmado sin constatación de posterior seguimiento e inicio de tratamiento con AAD.

- Actividades formativasy de apoyo a profesionales sanitarios/as, como alertas en la historia clínica electrónica para recordar la pertinencia del cribado del VHC en pacientes con exposiciones o situaciones de riesgo o con indicaciones clínicas.

- Simplificación de los modelos de atención evitando múltiples derivaciones, y adaptación de la atención a las personas con mayor vulnerabilidad.

- Integración de las actividades de prevención y cribado de la infección por VHC, VHB, VIH y otras ITS, y tuberculosis.

- Coordinación y atención multiprofesional en los centros de atención a personas con drogodependencias.

- Actividades de promoción del cribado dirigidas a población general y poblaciones específicas.

- Mejora de los sistemas de coordinación de los servicios de salud de las CCAA e Instituciones Penitenciarias, que permitan la continuidad asistencial de los pacientes que estando en situación de prisión provisional son puestos en libertad de forma inmediata.

Por último, se considera necesaria la incorporación de la perspectiva de equidad en salud e interseccionalidad en los programas de cribado, diagnóstico y tratamiento de la infección por el VHC. 


\section{ANTECEDENTES}

\subsection{Introducción}

Desde la aprobación del Plan Estratégico para el Abordaje de la hepatitis C en el Sistema Nacional de Salud (PEAHC) (1), la respuesta conjunta a la hepatitis C en España ha logrado grandes avances en su eliminación como problema de salud pública. Desde 2015 a finales de 2019 más de 135.000 personas han accedido a los tratamientos con antivirales de acción directa (AAD), con una tasa de respuesta viral sostenida superior al 95\% (2). En consecuencia, se ha observado una tendencia descendente de la prevalencia de infección activa por el virus de la hepatitis $\mathrm{C}(\mathrm{VHC})$ en algunas de las poblaciones más vulnerables (3-5); además se ha progresado en el conocimiento de la epidemiología de la infección activa en población general a través del 2 ㅇ Estudio de Seroprevalencia en España, información clave para la planificación de las acciones futuras (6).

Las actuales características de la situación epidemiológica de la infección por el VHC en España hacen que siga siendo un problema de salud pública, que requiere respuestas políticas, sanitarias y sociales de forma integrada, entendiendo que la prevención y el acceso equitativo al tratamiento deben ser la base de la acción. El diagnóstico y el tratamiento de la infección por el VHC suponen un beneficio tanto desde el punto de vista individual, como de salud pública, contribuyendo al control de la transmisión.

En el marco de la estrategia mundial del sector de la salud contra las hepatitis víricas 2016-2021, se han propuesto como metas globales (7) y europeas (8) el diagnóstico del 50\% de personas con infección crónica por VHC para 2020 y del $90 \%$ para 2030 , y el tratamiento del $75 \%$ de las personas diagnosticadas para 2020 y $80 \%$ para 2030. La Organización Mundial de la Salud (OMS) y el European Centre for Disease Prevention and Control (ECDC) han publicado en los últimos años recomendaciones en relación al diagnóstico de la infección por $\operatorname{VHC}(9,10)$. Como resultado de este compromiso global, diferentes gobiernos han puesto en marcha estrategias específicas sobre diagnóstico y tratamiento contra la hepatitis C (11-20).

Esta guía recoge las indicaciones del Ministerio de Sanidad sobre el cribado del VHC y la vinculación de las personas diagnosticadas al seguimiento y tratamiento de la hepatitis $C$ en España.

\subsection{Mecanismos de transmisión delVHCen España}

El VHC se transmite a través del contacto directo con sangre infectada. Más del $80 \%$ de las personas con infección por VHC refieren antecedentes de exposiciones de riesgo para la transmisión del VHC conocidas (21-23).

El uso compartido de materiales infectados como agujas y otros materiales de inyección para el consumo de drogas fue muy relevante en la transmisión del VHC durante la década de los años 80 en España, descendiendo desde mediados de los años 90 gracias a una disminución en el consumo de drogas inyectadas y a la generalización de los programas de reducción de daños (24). Aun así se recoge como una de las vías principales de transmisión de la infección en varias Comunidades Autónomas (CCAA) $(23,25,26)$. Se ha descrito un aumento de la incidencia y reinfecciones asociadas a la práctica de "chemsex", definida como el uso intencional de drogas psicoactivas para mantener relaciones sexuales entre hombres gais, bisexuales y otros hombres que tienen sexo con hombres (GBHSH), así como el uso 
intravenoso de estas sustancias para fines similares, práctica conocida como "slamming" o "slamsex" $(27,28)$. Por otro lado, se ha descrito riesgo de transmisión del VHC cuando se comparten instrumentos para consumo de drogas por vía inhalada, en especial si existen erosiones nasales, labiales $u$ orales $(9,29,30)$.

La transmisión sexual es muy poco eficiente. Se asocia fundamentalmente a prácticas sexuales con mayor riesgo de sangrado como el "fisting" o "chemsex", y con la presencia de VIH y otras infecciones de transmisión sexual (ITS) con ulceraciones genitales o proctitis (9), siendo otra de las vías de transmisión más frecuentes en la actualidad $(23,25,27,28)$.

La transmisión vertical del VHC se ha estimado en un 4-8\% entre madres sin infección por el VIH y en el 10-25\% entre madres con infección por el VIH (9).

La transmisión relacionada con la asistencia sanitaria es la vía de transmisión más relevante en algunos países con prevalencia alta de infección por el VHC. Entre las principales causas de transmisión se encuentran la esterilización inadecuada de material médico, sobre todo jeringas y agujas (9). En España este mecanismo fue importante antes de la introducción del empleo de material sanitario de un solo uso en 1975 y del refuerzo de otras medidas preventivas (24). Actualmente la transmisión es limitada, aunque sigue siendo descrita asociada a procedimientos quirúrgicos y diagnósticos invasivos $(23,25,26,31,32)$. Cada CCAA debe asegurar que en todos los centros, servicios y establecimientos sanitarios, señalados en el Real Decreto 1277/2003, de 10 de octubre, se cumplen los requisitos para la adecuada utilización de material sanitario. Es fundamental mejorar periódicamente el grado de información y conocimiento de los profesionales sanitarios sobre el riesgo de la transmisión del VHC asociada a la asistencia sanitaria y las medidas preventivas.

Se ha observado mayor riesgo de transmisión en personas receptoras de hemodiálisis crónica, con una alta variabilidad entre países (33) y entre unidades de hemodiálisis. En España, la prevalencia ha disminuido drásticamente desde 2001, debido, entre otras causas, a las medidas de prevención adoptadas en las unidades de hemodiálisis como el cribado del VHC al ingresar en las unidades y seguimiento posterior, siendo puntuales las seroconversiones y brotes por el VHC (34). En un estudio multicéntrico estatal realizado en 2011 en el que participaron 187 centros se describió una prevalencia del 5,6\% de infección crónica por el VHC en pacientes receptores de hemodiálisis crónica (34), y se estima que esta prevalencia haya disminuido tras la introducción de los AAD.

En cuanto a las intervenciones odontológicas, no se consideran una vía de transmisión del VHCen nuestro entorno, aunque sí pueden serlo las realizadas en centros que no cumplen las normas de seguridad $(35,36)$.

Las transfusiones de sangre, uso de hemoderivados y trasplantes de órganos de donantes no suponen una vía de transmisión en España desde 1990, año en que se inició la detección sistemática de marcadores del virus (24), no habiéndose declarado ningún caso de hepatitis $C$ en el sistema de hemovigilancia español desde esa fecha. La mayor parte de transfusiones se realizan en personas de edad avanzada o que tienen patologías crónicas que conllevan un estrecho seguimiento (37), por lo que la proporción actual de personas con antecedente de transfusión previa a 1990 que tiene infección por el VHC no diagnosticada se espera que sea muy limitada. 
En cuanto a las personas con riesgo de exposición accidental laboral a agentes biológicos, el riesgo de transmisión del VHC tras exposición percutánea se estima en un 1,8\% (0\%-7\%) (9). En el medio sanitario, entre 2001-2011 se notificaron 200 casos de hepatitis $C$ reconocidos como infecciones profesionales; sin embargo, se ha evidenciado una infradeclaración de los accidentes con riesgo biológico por lo que resulta difícil conocer su magnitud(38).

La realización de tatuajes y piercings se ha asociado a la transmisión del VHC, sobre todo fuera de los establecimientos sin las condiciones de seguridad necesarias, como puede suceder al compartir material o en centros penitenciarios $(39,40)$. También se ha sugerido en otros países la posibilidad de transmisión del VHC en centros de estética y peluquería a través de tratamientos como manicura o afeitado (41-43), si bien no disponemos de información actualizada en España.

\subsection{Situación epidemiológica y diagnóstico de infección por hepatitis Cen España}

\subsubsection{Prevalencia de infección por VHC}

La línea estratégica uno del PEAHC, orientada a cuantificar la magnitud del problema, describir las características epidemiológicas de las personas con infección por el VHC y establecer las medidas de prevención, proponía la realización de una encuesta de seroprevalencia de hepatitis $C$ en población adulta. Desde la Dirección General de Salud Pública del Ministerio de Sanidad en 2017 se desarrolló el 2o Estudio de Seroprevalencia en España con el objetivo de estimar la prevalencia y distribución del estado inmune frente a las enfermedades inmunoprevenibles y de la generada por infección natural por otros microrganismos, entre ellos el VHC. Los resultados de este estudio nos aportan información sobre la prevalencia de anticuerpos frente al VHCy de infección activa, y los factores asociados, en la población española en 2017 y 2018.

De acuerdo con estos resultados, en el ámbito de la población general se ha observado una prevalencia de anticuerpos frente al VHC de 0,85\% (IC 95\%: 0,64\%-1,08\%) y de infección activa de 0,22\% (IC 95\%: 0,12\%-0,32\%) en la población de 20 a 80 años entre 2017 y 2018 (6). Se ha identificado un patrón por sexo y año de nacimiento, con una prevalencia de infección activa más elevada en hombres nacidos entre 1958 y 1967, alcanzando el 0,86\%, y nacidos entre 1948 y 1957, con valor de $0,72 \%$, estando en los otros grupos por debajo de $0,20 \%$ (6). Según la situación socioeconómica, la prevalencia de infección activa fue de 0,31\% (IC95\%: 0,17\%-0,48\%) en el grupo de personas con clase social desfavorecida y del 0,54\% (IC95\%: 0,28\%-0,84\%) en personas con estudios primarios o inferiores, en contraste con una prevalencia de $0,12 \%$ (IC95\%: 0,00\%-0,29\%) en el grupo con clase social favorecida y del 0,05\% (IC95\%: 0,00\%-0,15\%) en personas con estudios universitarios (6).

La prevalencia de infección es superior en poblaciones que tienen exposiciones o situaciones de riesgo. Según el Observatorio Español de las Drogas y las Adicciones, entre las personas que han consumido drogas por vía inyectada alguna vez en la vida y que han sido admitidas a tratamiento por abuso o dependencia de sustancias psicoactivas, la prevalencia de anticuerpos frente al VHC fue de 61,4\% en 2017 (60,7\% en hombres y $65,1 \%$ en mujeres). La prevalencia de anticuerpos fue de $63,1 \%$ entre las que había utilizado la vía inyectada en el último año (62,7\% en hombres y $66,2 \%$ en mujeres) (44). No se dispone de datos de infección activa en esta población en esta fuente de información. Se prevé que la prevalencia de infección sea más elevada en las personas que se inyectan drogas y que no acuden a los centros de 
tratamiento, estimándose en otras revisiones un rango de prevalencia de 60 a 80\% (45). La prevalencia estimada de consumo de drogas inyectadas alguna vez en la vida en 2017 en España es del 0,4\% en la población entre 15 y 64 años, lo que supondría alrededor de 118.000 personas (46). La estimación del número de personas que se han inyectado drogas en el último año en 2017 fue de 13.136 (8.091-18.182) (44).

En 2018, la prevalencia de infección activa por el VHC en personas que tienen infección por VIH en seguimiento hospitalario en España ha variado entre el 3,7\% (IC 95\%: 2,9\%- 4,7\%) en el estudio de prevalencia de hepatitis virales realizado por GeSIDA (47), y el 6,5\% en la encuesta hospitalaria de pacientes con infección por el VIH realizado por el Centro Nacional de Epidemiología (48). La prevalencia de infección activa por el VHC en personas incluidas en la cohorte de la Red de Investigación en SIDA (CoRIS), que recoge casos con infección por el VIH naïve a tratamiento, pasó del 8,5\% en 2004 a 3,9\% en 2018 entre aquellos en los que se conocía su estado serológico (4). En los tres estudios se ha constatado una marcada tendencia descendente en los últimos años atribuida a la amplia difusión del tratamiento con AAD. Por otra parte, la incidencia global de reinfección por el VHC en personas coinfectadas por VIH/VHCque habían alcanzado respuesta viral sostenida tras el tratamiento con AAD entre 2014 y 2017 fue de 0,48 por 100 personas año (IC95\% 0,30-0,77), variando entre el 0,21 por 100 personas año (IC95\% 0,09-0,52) para personas ex usuarias de drogas inyectadas y el 5,93 por 100 personas año (IC95\% 3,37$10,44)$ para GBHSH (49). El aumento de la incidencia y la reinfección por el VHC en hombres que tienen sexos con hombres co-infectados por el VIH se ha asociado a la presencia de otras ITS y a la práctica de "chemsex" con "slamming" $(27,28,49)$.

Una aproximación a la prevalencia de infección por el VHC en GBHSH se puede extraer de la European MSM Internet Survey 2017 (EMIS2017) (50), una encuesta online autocumplimentada en la que participaron 10.634 hombres residentes en España en 2017. En ella el 1,8\% de los GBHSH refería haber sido diagnosticado de hepatitis $C$ alguna vez en la vida y el 0,4\% había sido diagnosticado en los últimos 12 meses. La presencia de infección por el VHCen GBHSH se ha asociado al consumo de drogas, prácticas sexuales de riesgo, y co-infección por VIH y otras infecciones de transmisión sexual $(51,52)$. Así, en los GBHSH que tenían infección por el VIH que participaron en la EMIS 2017, la prevalencia de infección activa por el VHC ascendía a 2,1\%, similar a lo descrito por los estudios sobre la cohorte CoRIS en 2018 (2,4\% de prevalencia de infección activa en GBHSH con diagnóstico reciente de VIH) (4) y algo superior a lo reportado por GeSIDA en 2017 (1,4\% en GBHSH en seguimiento hospitalario por VIH en España) (53) y por la Encuesta Hospitalaria en 2018 (1,7\% de los GBHSH que participaron en la encuesta tenía infección activa) (48).

El conocimiento de la epidemiología de la infección por el VHC en la población inmigrante en España es limitado. La prevalencia global estimada de anticuerpos frente a VHC es de 1,6\% aunque varía según procedencia, siendo más elevada entre migrantes de países de Europa del Este, Asia y África (54-56).

La prevalencia de anticuerpos e infección activa por el VHC en la población interna en centros penitenciarios ha descendido del $18,7 \%$ y $11,0 \%$ en 2016 al 10,2\% y 1,9\% en 2019, respectivamente, en relación con el tratamiento con AAD (3).

\subsubsection{Incidencia de nuevos diagnósticos de VHC}


En 2018 se declararon en la Red Nacional de Vigilancia Epidemiológica 1.494 nuevos diagnósticos de hepatitis $C$, de los cuales 66 correspondieron a casos nuevos de infección aguda, 762 a casos nuevos de infección crónica y en los 666 restantes no se dispuso de información sobre la clasificación del caso. La tasa global de incidencia fue de 3,39 nuevos diagnósticos por cada 100.000 habitantes. La información sobre la incidencia de nuevos diagnósticos es limitada y heterogénea entre CCAA en cuanto a la implantación de la vigilancia de nuevos diagnósticos de hepatitis $\mathrm{C}$ y al grado de exhaustividad en la recolección de datos y clasificación de los casos (57).

En la Región de Murcia, en la que la vigilancia de nuevos diagnósticos de hepatitis C se lleva realizando mediante búsqueda activa desde el año 2015 a través del Sistema de Información de Nuevos diagnósticos de Hepatitis C (SINHEPAC) (25), la incidencia anual media de nuevos diagnósticos de hepatitis $C$ en el periodo 2013-2017 fue de 8,7 casos por 100.000 habitantes con una ligera disminución en el periodo desde 9,3 por 100.000 en 2013 (137 casos) a 7,9 por 100.000 en 2017 (116 casos). En dicho periodo la incidencia de nuevos diagnósticos es mayor en hombres que en mujeres en todos los grupos de edad a

partir de los 30 años. Por edad, la incidencia es mayor en los grupos de edad de 40 a 59 en hombres y de 50 a 59 en mujeres, siendo similar a partir de los 60 años. De todos los casos en el periodo, un 5,3\% correspondía a infecciones agudas, un $65,2 \%$ a infecciones crónicas no diagnosticadas previamente y en el $29,4 \%$ no se pudo constatar la presentación clínica con certeza, si bien la gran mayoría correspondería a infecciones crónicas. En los casos de infección aguda, se conoce el probable factor de riesgo en el 88\% de los casos, siendo la categoría atribuible de transmisión más frecuente el uso actual de drogas intravenosas $(38,2 \%)$, seguido de contacto sexual en $26,5 \%$, procedimientos relacionados con la asistencia sanitaria en $8,8 \%$ y por último la exposición a material punzante $(2,9 \%)$. En el resto de los casos no se refirió factor de riesgo conocido.

En Navarra, en la que también se realiza vigilancia exhaustiva desde el año 2015, en el periodo 2015-2017 la tasa de nuevos diagnósticos de infección activa sin diagnóstico previo fue de 4,2 por 100.000 personas año (58). En 2018 se notificaron 34 nuevos diagnósticos de infección activa (incidencia de 5,2 por 100.000 habitantes), de los cuales el 53\% fue en mujeres, y sólo dos tenían evidencia de infección reciente, probablemente por exposición a inyección o inhalación de drogas.

\subsubsection{Diagnóstico de infección por el VHC y vinculación al tratamiento}

\section{Fracción de prevalencia no diagnosticada de infección por elVHC}

Como se ha indicado previamente en el apartado 1.3.1, la prevalencia de infección activa por el VHC en población de 20 a 80 años fue de $0,22 \%$ en 2017-2018. La fracción no diagnosticada fue del $29,4 \%$. En números absolutos se calcula que unas 76.457 personas en la población general tendrían infección activa en España, de las que 22.478 no estarían diagnosticadas en 2017-2018 (6).

Esta fracción no diagnosticada varía por sexo y edad; un $21,4 \%$ de los hombres y un $66,6 \%$ de las mujeres con infección activa no tenían diagnóstico previo de infección por VHC. En los grupos de hombres con mayor prevalencia de VHC por cohorte de nacimiento, la fracción no diagnosticada fue del 16\% en aquellos nacidos entre 1958 y 1967 y del $40 \%$ en los nacidos entre 1948 y 1957 . Todas las personas con infección no diagnosticada pertenecían a la clase social desfavorecida (6). 
De las personas con infección activa por el VHC diagnosticada previa a la realización del estudio de seroprevalencia, el 50\% había iniciado tratamiento con AAD, en el 17\% no hubo constancia de acceso al tratamiento con AAD (se asume por tanto que no se había vinculado a las personas al tratamiento), y no se disponía de esta información en el 33\% restante (6).

Según las fuentes que recogen la situación de las personas que han consumido drogas inyectadas en el último año o alguna vez en la vida y que han sido admitidas a tratamiento por abuso o dependencia de sustancias psicoactivas, en torno a un 30\% no conocían su estado serológico para el VHC en 2017, porcentaje similar por sexo, y algo superior en menores de 34 años (44). Teniendo en cuenta las estimaciones mencionadas en el apartado anterior sobre número de personas que se inyectan drogas, se podría calcular un mínimo de 3.940 personas que han consumido drogas por vía inyectada en el último año y desconocen su estado serológico para el VHC. Probablemente este número sea superior, ya que se podría esperar una fracción no diagnosticada más elevada en las personas que consumen drogas inyectadas y no acuden a los centros de tratamiento.

La fracción de prevalencia de la infección por el VHC diagnosticada en las personas que tienen infección por el VIH es superior que en la población general: el 85,6\% de las personas con infección por VIH naïve a tratamiento conocía su estado serológico en el estudio de la cohorte CoRIS entre 2004 y 2018 (59), y ascendía hasta el 99,3\% en las personas con infección por el VIH en seguimiento hospitalario en 2018 según el estudio realizado por GeSIDA (47).

En los centros penitenciarios se ofrece la prueba del VHC a todas las personas internas en el primer mes desde el ingreso en prisión y durante su estancia en función de sus exposiciones de riesgo (60). La cobertura actual de la prueba está en torno al $80 \%$ de las personas internas, limitada sobre todo en personas con estancias cortas en los centros.

\section{Presentación tardía de la infección por el VHC para la atención sanitaria}

La presentación tardía de la infección crónica por el VHC para la atención sanitaria ha sido definida por el ECDC y la EASL (European Association for the Study of the Liver) como la presencia de fibrosis $\geq$ F3 (presentación con enfermedad hepática avanzada), cirrosis descompensada o hepatocarcinoma (presentación con enfermedad hepática tardía) en una persona sin tratamiento previo $(10,61)$. La presentación tardía supone peores resultados en salud para la persona afectada y una mayor probabilidad de transmisión de la infección en la población. Las principales explicaciones en términos de la actividad del sistema sanitario son una detección tardía de la infección, una vinculación deficiente de las personas diagnosticadas al seguimiento y tratamiento, y un tiempo excesivo entre el cribado y el diagnóstico completo y tratamiento $(61,62)$.

En 2018, un estudio realizado en 11 hospitales de 8 CCAA (63) observó una prevalencia de presentación tardía de la infección por el VHC en el 26,1\% de los pacientes que acudían por primera vez a consulta de hepatología, con porcentajes superiores en hombres y en mayores de 60 años; no se describió el tiempo entre la primera detección de la infección y la consulta.

En la Región de Murcia se ha constatado mediante vigilancia epidemiológica (25) que de las personas con nuevos diagnósticos de infección no aguda por VHC de las que se conocía su estadio de fibrosis durante 
el periodo 2013-2017, el 43,8\% presentó diagnóstico tardío. El porcentaje de notificaciones con diagnóstico tardío ha descendido desde 2013 (52,9\%) a 2017 (35,8\%). La mediana de tiempo entre la serología positiva de VHC y la realización de elastografía fue de 4,6 meses en el año 2017, siendo igual o mayor de 7,7 meses en el $25 \%$ de los casos.

En Navarra, el 35\% de los casos con nuevo diagnóstico de infección activa por el VHC en 2018 presentó diagnóstico tardío. En este cálculo se incluyeron las infecciones agudas además de las crónicas, aunque la mayoría de los diagnósticos no tenían evidencia de transmisión reciente.

\section{OBJETIVOY ÁMBITODE APLICACIÓN}

\subsection{Objetivo general}

Promover el cribado de la infección por el VHC y la vinculación de las personas diagnosticadas al seguimiento y tratamiento.

\section{2. Ámbito de aplicación}

Las recomendaciones están dirigidas a facilitar al personal sanitario la información y el apoyo activo necesarios para la realización de la prueba de VHC, la identificación de personas previamente diagnosticadas y su posterior vinculación al tratamiento, en el ámbito de la Atención Primaria y Comunitaria, Atención Hospitalaria, Penitenciaria, Drogodependencias y Salud Pública en España.

\section{MÉTODO DE ELABORACIÓN DE LAS RECOMENDACIONES}

Estas recomendaciones han sido coordinadas y elaboradas por la Secretaría del Plan Nacional sobre el SIDA en colaboración con la Unidad de Programas de Cribado en la Dirección General de Salud Pública, Calidad e Innovación del Ministerio de Sanidad. El proceso de elaboración, en el que han participado personas expertas relacionadas con el diagnóstico y tratamiento del VHC, ha consistido en las siguientes actividades:

- Revisión de guías y recomendaciones de diferentes países (11,12,64,13-20,65), OMS (9) y ECDC (10). Se realizó además una amplia búsqueda bibliográfica en la literatura española e internacional.

- Grupo técnico de cribado de la infección por el VHC.

El Grupo fue constituido en junio de 2019 para asesorar sobre las estrategias de cribado de la infección por el VHC en España. Está comprendido por representantes del Ministerio de Sanidad (Dirección General de Salud Pública, Calidad e Innovación: Secretaría del Plan Nacional sobre el SIDA y Unidad de Programas de Cribado de la Subdirección General de Promoción de la Salud y Vigilancia en Salud Pública; Dirección General de Cartera Básica de Servicios del Sistema Nacional de Salud y Farmacia; y Delegación del Gobierno para el Plan Nacional sobre Drogas: Unidad de Sistemas de Información y Documentación), Subdirección General de Coordinación de Sanidad Penitenciaria del Ministerio del Interior, Comunidades Autónomas (Servicios de Epidemiología y Servicios responsables de los planes de cribado y de los planes de hepatitis C), Centro Nacional de Epidemiología - Instituto de Salud Carlos III, Consejo Asesor Científico del PEAHC, Sociedades 
Científicas de Atención Primaria, Hepatología, Enfermedades Infecciosas y Microbiología, y Sanidad Penitenciaria, y Asociaciones de Pacientes y ONGs.

- Recopilación de intervenciones realizadas en las CCAA relacionadas con el cribado del VHC y vinculación de las personas al seguimiento y tratamiento. Las intervenciones se describen en el apéndice 2, destacando en el texto de la guía la referencia a éstas cuando corresponda.

- Las recomendaciones tratan de incorporar de manera transversal el enfoque de desigualdades sociales en salud $(66,67)$, que se considera prioritario para garantizar la equidad y la calidad de los servicios de diagnóstico y tratamiento de las personas con hepatitis $\mathrm{C}$.

\section{MARCO GENERAL DE LOS PROGRAMAS DE CRIBADO}

A efectos de la Ley 33/2011, de 4 de octubre, General de Salud Pública se entiende por cribado aquellas actividades orientadas a la detección precoz de la enfermedad, su diagnóstico y tratamiento temprano, que se ofrecen activamente al conjunto de la población susceptible de padecer la enfermedad, aunque no tenga síntomas ni haya demandado ayuda médica.

La detección precoz mediante cribado se puede efectuar en el marco de programas definidos de cribado poblacional, o bien mediante una actividad oportunista, que es no sistemática y se suele realizar dentro de los servicios de salud a petición de la persona interesada o aprovechando una consulta por otro motivo médico. Además de los programas de cribado dirigidos a grupos extensos de población según características demográficas, otras estrategias pueden ser necesarias dirigidas a las personas más vulnerables.

Los programas de cribado poblacional son unos de los programas preventivo-asistenciales esenciales en salud pública y corresponde a las autoridades sanitarias establecer las líneas generalesque deben seguir las políticas en esta materia. Son programas organizados y coordinados generalmente desde Salud Pública y en los que se realiza una invitación activa a toda la población diana utilizando habitualmente como fuente de información demográfica poblacional el padrón o en algunos casos la tarjeta sanitaria.

Estos programas deben guiarse por los principios recogidos en Ley General de Salud Pública de equidad, de pertinencia, de precaución, de evaluación, de transparencia, de integralidad y de seguridad y además deben reunir una serie de criterios destacando entre otros la necesidad de mostrar evidencia sobre la eficiencia o el coste-efectividad del programa, comparando los costes y los beneficios en salud del cribado frente a la detección mediante diagnóstico clínico. Esta comparación permite considerar si el coste añadido de una intervención sanitaria, como la puesta en marcha de un programa de cribado poblacional está justificado por los beneficios en salud que reporta a la población.

La incorporación de un programa de cribado poblacional a la cartera común de servicios viene precedida de una evaluación por parte de la Red Española de Agencias de Evaluación de Tecnologías Sanitarias y Prestaciones del Sistema Nacional de Salud y no se incluyen en la cartera común de servicios aquellas técnicas, tecnologías y procedimientos cuya contribución eficaz a la prevención, diagnóstico, tratamiento, rehabilitación y curación de las enfermedades, conservación o mejora de la esperanza de vida, autonomía y eliminación o disminución del dolor y el sufrimiento no está suficientemente probada. 
En cuanto a programas de cribado según exposiciones de riesgo, de acuerdo con el Real Decreto 1030/2006 el cribado del VHC en poblaciones que presentan exposiciones de riesgo es una actividad que ya estaría considerada dentro de la cartera común de servicios y que queda recogida en los siguientes apartados:

Anexo II "Cartera de servicios comunes de atención primaria"

"6.4 Atención al adulto, grupos de riesgo y enfermos crónicos: Comprende, en general, la valoración del estado de salud y de factores de riesgo, los consejos sobre estilos de vida saludables, la detección de los problemas de salud y valoración de su estadio clínico, la captación del paciente para el seguimiento clínico adecuado a su situación, la atención y seguimiento de personas polimedicadas y con pluripatología y la información y consejo sanitario sobre su enfermedady los cuidados precisos al paciente y cuidador/a, en su caso.

6.4.2 Atención de personas con VIH y enfermedades de transmisión sexual con el objeto de contribuir al seguimiento clínico y mejora de su calidad de vida y evitar las prácticas de riesgo.

\subsubsection{Atención a personas con conductas de riesgo:}

(...) Atención a otras conductas adictivas. Incluye la detección, la oferta de apoyo sanitario especializado, si se precisa, para abandono de la dependencia y la prevención de enfermedades asociadas.

6.4.5 Detección precoz y abordaje integrado de los problemas de salud derivados de las situaciones de riesgo o exclusión social, como menores en acogida, minorías étnicas, inmigrantes u otros."

Sin embargo, dado que en esta norma no se han detallado los criterios de acceso a esta prestación en relación con la hepatitis $C$, en estos momentos se están aplicando criterios distintos en las diferentes comunidades y ciudades autónomas dentro de los programas establecidos por cada servicio de salud.

Por ello es necesario definir los elementos mínimos comunes que permitan ofertar esta prestación de forma homogénea en todo el Sistema Nacional de Salud garantizando la equidad en el acceso de toda la población a la que va dirigida.

\section{PRINCIPIOS BÁSICOS DE LA REALIZACIÓN DE LA PRUEBA DE VHC}

Como con cualquier otra prueba, las utilizadas para realizar el cribado y diagnóstico de la infección por el VHC debe seguir los principios básicos que figuran a continuación:

- La prueba es voluntaria (excepto en los supuestos recogidos en el Punto 6.1.2.1), confidencial, y previo consentimiento informado verbal de la persona a la que se le realiza.

- Debe ser accesible a toda la población y estar disponible de forma gratuita.

- Se recomienda un consejo post-prueba que incluya la prevención de la infección o reinfección, así como debe garantizarse la derivación a los servicios adecuados y el acceso al tratamiento oportuno a todas las personas con resultado positivo. 


\section{INDICACIONES PARA EL CRIBADO DE LA INFECCIÓN POR EL VHC}

\subsection{Indicaciones de realización de la prueba del VHC}

\subsubsection{Personas con criterios clínicos compatibles con infección por el VHC}

Se debe descartar infección por el VHC en todas las personas con sospecha clínica de hepatitis viral aguda o crónica.

Alrededor de un 15-30\% de las personas con infección aguda presentan manifestaciones clínicas tras la exposición. Éstas son inespecíficas e incluyen astenia, náuseas, pérdida de apetito, dolor abdominal, prurito, febrícula, mialgias, artralgias, debilidad, pérdida de peso, coluria, acolia e ictericia (68).

Trasla infección aguda, aproximadamente un 15-45\% de las personas eliminan el virus espontáneamente en un plazo de seis meses, sin necesidad de tratamiento. Se estima que el restante $55-85 \%$ desarrollan hepatitis $C$ crónica, de las que entre el 15-30\% evoluciona a cirrosis hepática tras 20 años de la infección (9). La variabilidad en la progresión a infección crónica y a estadios avanzados depende de la metodología utilizada en los estudios y de las características de la población analizada $(69,70)$.

La mayoría de pacientes con hepatitis C crónica no presenta síntomas o son inespecíficos. El síntoma más frecuente es la fatiga, otros son artralgias, mialgias, pérdida de peso, debilidad y alteraciones cognitivas. La cirrosis compensada también puede ser asintomática. Existe riesgo de aparición de complicaciones de la hipertensión portal, como ascitis, hemorragia por varices esofágicas, encefalopatía hepática, o de carcinoma hepatocelular (71).

Los niveles de transaminasas suelen ser algo elevados aunque varían a lo largo de la evolución y pueden ser normales hasta en un tercio de los pacientes (71). Se debe descartar infección por el VHC en todas las personas con pruebas de función hepática alterada.

Las comorbilidades más frecuentes en pacientes con infección por el VHC, más allá de las hepáticas, son depresión, diabetes mellitus y enfermedad renal crónica. Una proporción de esta morbilidad se atribuye directamente al VHC, encontrándose manifestaciones extrahepáticas en alrededor de un tercio de los pacientes infectados, tales como linfoma no Hodgkin, crioglobulinemia mixta esencial, vasculitis, síndrome seco, glomerulonefritis membranoproliferativa, porfiria cutánea tarda, liquen plano, disfunción endotelial o astenia $(71,72)$.

\subsubsection{Personas sin signos ni síntomas de infección por VHC}

\subsubsection{Realización obligatoria de la prueba del VHC}

La realización de la prueba de detección del VHCes un requisito de verificación obligatorio en los centros de transfusión para la donación de sangre, células y tejidos (incluidas células reproductoras) y de trasplante de órganos (73-76). 


\subsubsection{Oferta dirigida de la prueba del VHC}

\section{Cribado de infección por el VHC en personas con antecedentes de exposición o situación de riesgo}

Más del $80 \%$ de las personas que tienen infección por el VHC refiere exposiciones o situaciones de riesgo para la transmisión del VHC (21-23). El cribado de la infección por el VHC en estas personas supone un beneficio, tanto a nivel individual como poblacional, ya que permite adoptar medidas que disminuyan el riesgo de transmisión de la enfermedad $(9,10)$.

El cribado del VHC está indicado en las personas que tienen las exposiciones y situaciones de riesgo para la infección por el VHC recogidas en la tabla 1.

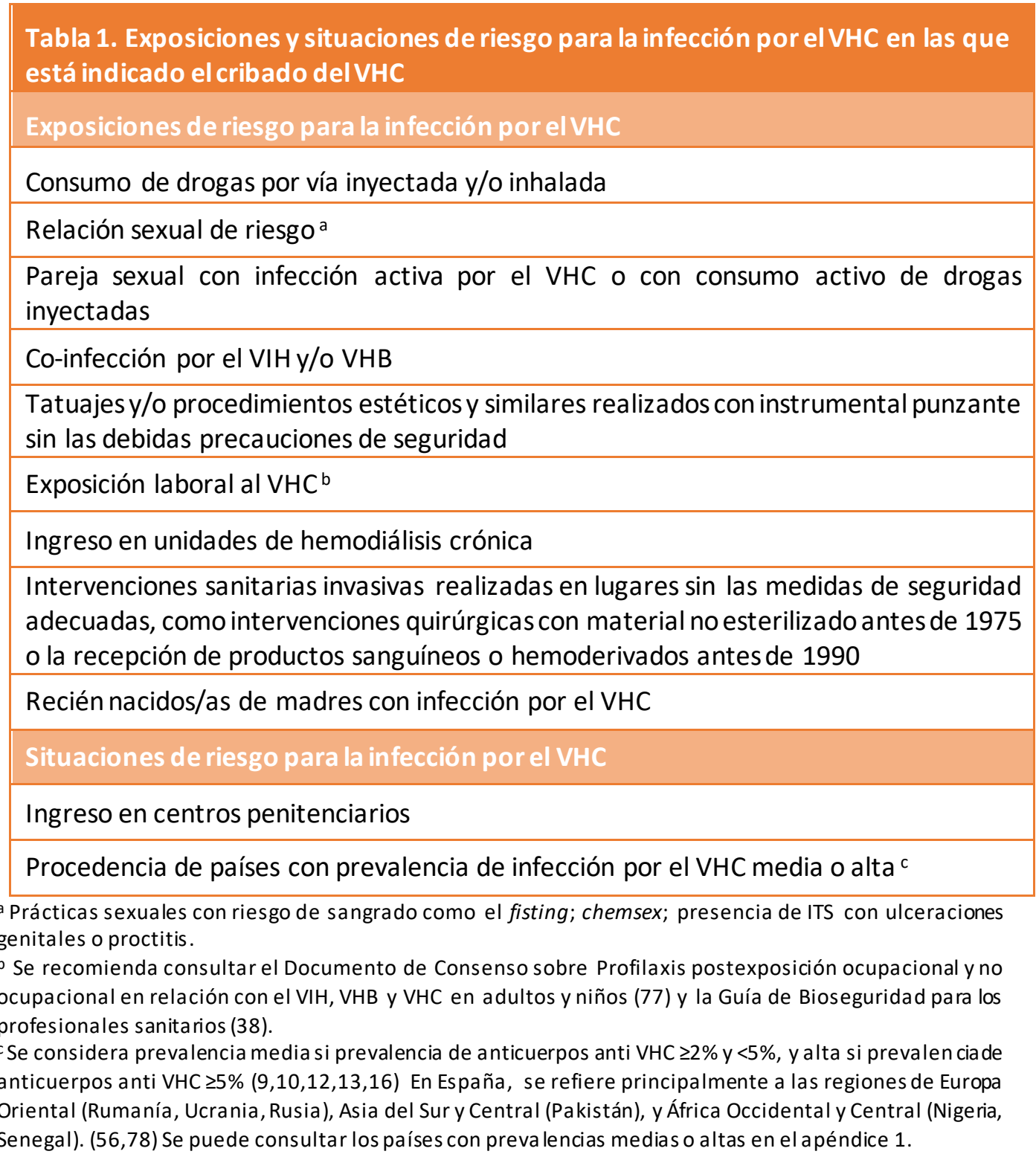




\section{Cribado de la infección por el VHC en personas sin signos ni síntomas y sin antecedentes de exposición o situaciones de riesgo}

En España no se recomienda el cribado de la infección por el VHC en personas sin exposiciones de riesgo en base a la evidencia considerada $(6,9,10,79-81)$.

Esta recomendación está alineada con otros países europeos como Reino Unido $(13,14)$, Alemania (11), Francia (15), Irlanda (16), y países similares como Canadá (12) o Australia (20), que han implementado estrategias de cribado por factores de riesgo, basándose en la epidemiología local y en evaluaciones independientes como las de la Canadian Task Force on Preventive Health Care, el Institute for Quality and Efficiency in Health Care de Alemania o el NICE de Reino Unido.

Aunque más del $80 \%$ de las personas con infección por el VHC refiere antecedentes de riesgo para la transmisión del VHC, en alrededor de un $20 \%$ no se identifica ninguna exposición conocida (21-23). Por otro lado, se ha descrito cierta dificultad en la identificación de exposiciones o situaciones de riesgo en los centros sanitarios, relacionada con el tiempo restringido de consulta, miedo a estigmatización, escasa sensibilización o dificultad de los pacientes para recordarlos, entre otros. Además, la prevalencia superior en las personas nacidas antes de 1967 estaría relacionada en parte con la reutilización de material sanitario sin esterilizar, que fue una exposición generalizada y por la que no sería muy eficiente preguntar. Por estos motivos, dentro del Grupo técnico se valoró la pertinencia de considerar el cribado en personas pertenecientesa cohortes de nacimiento con mayor prevalencia.

Con el objeto de actualizar la información necesaria para la toma de decisiones en el Sistema Nacional de Salud y de analizar si el cribado poblacional del VHC por cohortes de nacimiento también cumple con los requisitos para que se incluya dentro de la cartera común de servicios y se implante en todo el territorio, se ha iniciado el procedimiento de evaluación de este cribado poblacional. Desde la Dirección Generalde Salud Pública, Calidad e Innovación del Ministerio de Sanidad se ha solicitado a la Red de Agencias de Evaluación de Tecnologías Sanitarias y Prestaciones del SNS, dentro del plan de trabajo 2020, un informe sobre la evidencia de la eficacia clínica y del coste efectividad del cribado poblacional de esta enfermedad.

Así se completará la información relevante (eficacia clínica y coste-efectividad) necesaria de acuerdo con el Real Decreto 1030/2006, de 15 de septiembre, por el que se establece la cartera de servicios comunes del Sistema Nacional de Salud y el procedimiento para su actualización, para la toma de decisión sobre la incorporación de un programa de cribado poblacional del VHCa la cartera común de servicios del SNS.

Si tras esta evaluación, el cribado poblacional del VHC por cohortes de nacimiento cumple los criterios reglamentariamente establecidos para las prestaciones que pueden formar parte de la cartera común de servicios del SNS, este programa de cribado podrá ser incorporado a dicha cartera.

\subsection{Técnicas de laboratorio para el diagnóstico y diagnóstico en un solo paso}

En general, el cribado debe estar basado en una prueba inicial de detección de anticuerpos frente al VHC, con posterior confirmación de la infección con marcadores virológicos como ARN del VHC (82) o antígeno core (Ag Core) (83). 
Un resultado positivo en una primera serología debe confirmarse con una determinación de viremia en la misma muestra. El diagnóstico en un solo paso contribuye a mejorar la vinculación con la atención sanitaria y disminuye el tiempo de acceso al tratamiento $(10,84,85)$. En España, la implementación del diagnóstico en un solo paso en los hospitales ha aumentado significativamente en los dos últimos años (apéndice 2.1).

En el caso de sospecha de infección aguda por el VHC, en recién nacidos de madres con infección por el VHC y en algunas personas inmunodeprimidas se realizará la detección de marcadores virológicos independientemente del resultado de la prueba de anticuerpos (82).

En pacientes con infección resuelta con continuación de la exposición de riesgo para la reinfección se recomienda la determinación de marcadores virológicos directamente. En este escenario no procede la repetición de pruebas serológicas (9).

Los ensayos más utilizados para la detección de anticuerpos frente al VHC son los enzimoinmunoensayos (EIA) o los inmunoensayos quimioluminiscentes (CLIA). Los de tercera generación detectan anticuerpos a antígenos recombinantes del core, NS3, NS4 y NS5 (82).

La detección del Ag Core también se considera apta para cribado y diagnóstico $(9,85)$, incluso superior a los anticuerpos para identificar los casos de infección aguda $(86,87)$. Aunque presenta menor sensibilidad que la PCR para detectar por debajo de 500-3.000 UI/ml de ARN, supone un menor coste y más rapidez en la obtención de resultados $(82,83,85)$.

Cuando sea necesario para facilitar el acceso al cribado del VHC se recomienda utilizar las pruebas de diagnóstico rápido del $\operatorname{VHC}(9,10,82,88)$. Actualmente se encuentran comercializadas diferentes pruebas rápidas de anticuerpos frente al VHC basadas en técnicas de inmunoadherencia por inmunofiltración o inmunocromatografía, que pueden utilizarse en muestras de suero, sangre capilar, plasma o saliva $(82,89,90)$. En cuanto a pruebas rápidas de detección de viremia, hay varias disponibles que identifican el ARN del VHC a partir de sangre capilar, así como el Ag Core (90).

Por otro lado, el uso de muestras de sangre seca capilar obtenidas por punción dactilar también puede facilitar la realización de la prueba en diferentes entornos y el diagnóstico en un solo paso $(9,91)$, aunque se encuentra aún pendiente de aprobación por las entidades reguladoras (90).

La utilización de las pruebas rápidas y en el punto de atención al paciente debe respetar siempre el marco legislativo vigente en materia de transporte y realización de pruebas de diagnóstico in vitro (92).

Para establecer las estrategias de cribado y diagnóstico más adecuadas para cada ámbito será necesario tener en cuenta diferentes criterios, como la aceptabilidad, sensibilidad y coste de cada tipo de prueba, la disponibilidad de recursos, o la necesidad de ofrecer resultados y orientación en una misma consulta.

\subsection{Frecuencia de realización de la prueba}

Se recomienda ofrecer de manera proactiva las pruebas del VHC una vez en la vida a todas las personas con las exposiciones o situaciones de riesgo indicadas. Se debe repetir la prueba si se refiere exposición de riesgo continuada y con elección de la técnica según estado serológico previo. La frecuencia orientativa 
recomendada es entre 6 y 12 meses según la exposición, la epidemiología local y evaluación personalizada del riesgo (10).

\subsection{Lugares donde realizar la prueba}

Se debe realizar la prueba en todos los centros sanitarios. Se propone tanto una captación con invitación activa como a petición de la persona interesada y aprovechando el contacto con el sistema sanitario en los centros de atención primaria y hospitalaria.

Por otrolado, se recomienda ofrecer de manera proactiva la prueba en los centros sanitarios que atienden específicamente a personas con exposiciones de riesgo como los centros de atención a personas con ITS o personas con drogodependencias, así como en las unidades móviles autorizadas en campañas y para acercar el cribado a poblaciones con dificultades de acceso a los centros sanitarios.

Se debe ofertar la prueba a todas las personas a su ingreso en un centro penitenciario, y repetirla según valoración personalizada del riesgo.

Se indica la realización de la prueba en las visitas de seguimiento del embarazo a aquellas mujeres que tengan las exposiciones o situaciones de riesgo indicadas. No está indicado el cribado para mujeres embarazadas sin exposiciones o situaciones de riesgo.

El objetivo de esta guía no aborda la realización de pruebas en el entorno comunitario ni se detallan las recomendaciones de utilización de pruebas rápidas, ya que por su complejidad, se considera más apropiado hacerlo en un marco específico.

\section{RECOMENDACIONES PARA MEJORAR EL ACCESO AL CRIBADO Y VINCULACIÓN DE LAS PERSONAS DIAGNOSTICADAS AL SEGUIMIENTOY TRATAMIENTO}

Se han descrito diferentes barreras generales para el acceso de la población al cribado y a la vinculación al seguimiento y tratamiento de la infección por el VHC. Es necesario identificar las barreras y facilitadores de acceso y uso de los servicios en cada contexto, adecuando la atención sanitaria a las diversas necesidades de las personas y garantizando su universalidad.

Para ello se propone la coordinación interinstitucional entre administraciones públicas sanitarias y la coordinación intersectorial, para colaborar en la mejora del acceso al diagnóstico con los dispositivos asistenciales que atienden a personas con exposiciones o situaciones de riesgo para el VHC.

La implementación de intervenciones específicas por parte de diferentes actores debe estar coordinada con los servicios sanitarios y de salud pública del territorio correspondiente.

\subsection{Actividades formativas y de apoyo a profesionales sanitarias/os}

Para incrementar el diagnóstico en los centros sanitarios se recomienda implementar actividades de formación y sensibilización para profesionales, así como actividades que faciliten la identificación de pacientes con exposiciones y situaciones de riesgo (9). Algunas CCAA han desarrollado alertas en la historia clínica electrónica de Atención Primaria que recuerdan al personal sanitario la pertinencia de 
detectar la presencia del VHC en, por ejemplo, pacientes con registro de infección por el VIH y otras ITS (apéndice 2.2).

\subsection{Actividades de promoción del cribado dirigidas a población generaly poblaciones espećficas}

Se recomienda fomentar acciones de sensibilización a la población general sobre el cribado del VHC según las exposiciones de riesgo indicadas; en el apéndice 2.3 se describen algunascampañas y otras actividades de difusión.

Se recomienda trabajar conjuntamente con entidades y administraciones locales para la promoción del cribado con poblaciones específicas. Por ejemplo, en el apéndice 2.4 se puede consultar una intervención piloto en el ámbito comunitario para la promoción del cribado del VHCen personas procedentes de países con alta prevalencia.

\subsection{Búsqueda e identificación activa de personas con necesidad de vinculación al seguimiento y tratamiento en los registros sanitarios}

Se recomienda la búsqueda e identificación activa de personas que tienen una prueba de anticuerpos frente al VHC positiva en algún registro sanitario sin constatación de confirmación del diagnóstico, así como de personas con diagnóstico de viremia confirmado sin constatación de posterior seguimiento e inicio de tratamiento con AAD.

La identificación de los pacientes por parte de las autoridades de Salud Pública de las CCAA o de los Servicios de Salud, tanto en la historia clínica electrónica como otros registros, y la posterior comunicación a los profesionales sanitarios en ejercicio en los servicios de Atención Primaria u Hospitalaria que correspondan, forma parte de sus competencias y actividad ordinaria. Por este motivo, y siempre salvo criterio distinto del delegado de protección de datos de cada Comunidad Autónoma, se considera que no sería necesario preservar los datos de identificación personal del paciente separados de la información de carácter clínico asistencial ni el consentimiento de la persona afectada. En coordinación con los delegados de protección de datos de las CCAA, los profesionales de los servicios clínicos podrán contactar con dichos pacientes para posibilitar su vinculación al seguimiento clínico y tratamiento. Estas recomendaciones se encuentran amparadas en el marco legislativo vigente por la Ley Orgánica 3/2018, de 5 de diciembre, de Protección de Datos Personales y garantía de los derechos digitales; la Ley 33/2011, de 4 de octubre, General de Salud Pública y la Ley 41/2002, de 14 de noviembre, básica reguladora de la Autonomía del Paciente y Derechos y Obligaciones en materia de información y documentación clínica.

Varias CCAA han implementado esta medida de diferentes maneras, siendo imprescindible la implicación y coordinación entre diferentes profesionales sanitarios. La búsqueda de pacientes en registros electrónicos se ha llevado a cabo por autoridades tanto de Salud Pública como de Asistencia Sanitaria, incluyendo los Servicios Centraleso los Servicios de Admisión de los centros sanitarios. En el apéndice 2.5 se describen tres experiencias de manera más detallada. 


\subsection{Simplificación de la atención e integración de las actividades relacionadas con otras patologías relacionadas y drogodependencias.}

Taly como se ha señalado a lo largo de este documento, resulta imprescindible simplificar los modelos de atención evitando múltiples derivaciones y adaptar la atención al entorno de las personas con mayor vulnerabilidad a la infección como las personas sin hogar, algunas poblaciones migrantes, personas que consumen drogas, personas en prisión y otras situaciones de vulnerabilidad (93).

En esta línea, resulta efectivo integrar las actividades de prevención y cribado del VHC y de la infección por el VHB, VIH y otras ITS, tanto en los centros de atención primaria y especializada como en los centros específicos de atención a personas con ITS o a personas migrantes (9). En el ámbito comunitario, destaca el trabajo de las organizaciones sociales del ámbito de la prevención del VIH y otras ITS, que constituyen un apoyo fundamental para la vinculación al cribado y al tratamiento en los servicios de salud (apéndice 2.6). Por otro lado, también resulta de utilidad la valoración de las exposiciones de riesgo de infección por el VHC, y cribado en su caso, en las personas con diagnóstico de tuberculosis (9).

El trabajo coordinado con los servicios comunitarios, de atención primaria y de atención especializada a la salud mental y a las drogodependencias ha mostrado un mejor acceso al cribado y vinculación y adherencia al tratamiento del VHC de las personas que consumen drogas y las personas con problemas de salud mental (9). Entre las intervenciones que están mostrando mayor aceptación en diferentes municipios se encuentra la atención multiprofesional en los centros de atención a personas con drogodependencias, incluyendo la realización de las pruebas de hepatitis víricas y VIH y dispensación del tratamiento en el mismo centro. En el apéndice 2.7 se muestran varias experiencias relacionadas.

\subsection{Coordinación de los servicios de salud e Instituciones Penitenciarias para la continuidad asistencial}

Se considera prioritario incrementar y/o mejorar los sistemas de coordinación de los servicios de salud de las CCAA e Instituciones Penitenciarias, que permitan la continuidad asistencial de los pacientes diagnosticados y/o en tratamiento y que estando en situación de prisión provisional son puestos en libertad de forma inmediata. En el apéndice 2.8 se describe un ejemplo de coordinación interprofesional para la atención de pacientes internos en los centros.

\section{ENFOQUE DE EQUIDAD EN LOS PROGRAMAS DE CRIBADO DEL VHC}

Se considera necesaria la incorporación de la perspectiva de equidad en salud (94) e interseccionalidad (95) en todas las fases de los programas de cribado, diagnóstico y tratamiento de la infección por el VHC.

Se ha identificado cierta vulnerabilidad a la infección por VHC y desigualdades en el acceso a los servicios de salud relacionadas con procesos de exclusión social según identidad de género (especialmente en personas trans), orientación sexual, prostitución, migración, ingreso en prisión, sinhogarismo y otras condiciones socioeconómicas $(10,24,41,96-100)$.

En cuanto al diagnóstico del VHC, los resultados del estudio de prevalencia en población general sugieren prestar especial atención a las desigualdades por géneroy clase social, con una fracción no diagnosticada 
de prevalencia de VHC superior en mujeres y en el grupo de personas pertenecientes a clase desfavorecida (6).

También son destacables las desigualdades y barreras que afectan a las personas que consumen drogas por vía inyectada, como las generadas por las condiciones socioeconómicas o el estigma y discriminación social y de profesionales (101). Pueden afectar especialmente a mujeres que se inyectan drogas, encontrando mayor exclusión de los servicios de diagnóstico y tratamiento $(102,103)$. Además de la de los servicios de salud, otras medidas deben ser consideradas para un abordaje más integral de estas inequidades.

\section{EVALUACIÓN DE LAS RECOMENDACIONES}

La evaluación de estas recomendaciones se realizará de manera integrada en la monitorización del conjunto de la respuesta a las hepatitis víricas. Se incorporarán las conclusiones del informe de eficacia clínica y coste-efectividad de las estrategias de cribado que actualmente se encuentra en proceso de elaboración por la Red Española de Agencias de Evaluación de Tecnologías Sanitarias y Prestaciones del SNS. 


\section{APÉNDICES}

Apéndice 1. Países con prevalencia media o alta de anticuerpos anti-VHC.

\begin{tabular}{|c|c|c|c|}
\hline País & Prevalencia anti-VHC & País & Prevalencia anti-VHC \\
\hline Albania & 2,4 & Letonia & 2,4 \\
\hline Angola & 4,2 & Líbano & 3,1 \\
\hline Armenia & 5,4 & Liberia & 5,3 \\
\hline Azerbaiyán & 3,1 & Lituania & 2,9 \\
\hline Bahrein & 3,1 & Mali & 5,3 \\
\hline Benín & 3,6 & Moldavia & 3,3 \\
\hline Burkina Faso & 5,3 & Mongolia & 10,8 \\
\hline Camboya & 2,3 & Níger & 5,3 \\
\hline Camerún & 11,6 & Nigeria & 8,4 \\
\hline Cabo Verde & 5,3 & Omán & 3,1 \\
\hline Rep.Centroafricana & 4,2 & Pakistán & 5,0 \\
\hline Chad & 5,3 & Palestina & 3,1 \\
\hline Congo & 4,2 & Puerto Rico & 2,3 \\
\hline Rep.Democrática de Congo & 4,3 & Rumanía & 3,2 \\
\hline Costa de Marfil & 3,3 & Rusia & 4,1 \\
\hline Egipto & 15,7 & Santo Tomé y Príncipe & 5,3 \\
\hline Guinea Ecuatorial & 4,2 & Senegal & 5,3 \\
\hline Estonia & 3,3 & Sierra Leona & 5,3 \\
\hline Gabón & 11,2 & Siria & 3,1 \\
\hline Gambia & 2,1 & Taiwán & 4,4 \\
\hline Georgia & 6,7 & Tayikistán & 3,1 \\
\hline Ghana & 5,3 & Tailandia & 2,7 \\
\hline Guinea & 5,3 & Togo & 5,3 \\
\hline Guinea-Bissau & 5,3 & Turkmenistán & 5,6 \\
\hline Iraq & 3,2 & Ucrania & 3,6 \\
\hline Italia & 4,4 & Emiratos Árabes Unidos & 3,1 \\
\hline Jordania & 3,1 & Uzbekistán & 11,3 \\
\hline Kazajistán & 3,3 & Sahara Occidental & 3,1 \\
\hline Kuwait & 3,1 & Yemen & 2,2 \\
\hline Kirguistán & 2,5 & & \\
\hline
\end{tabular}

Fuente: European Centre for Disease Prevention and Control. Epidemiological assessment of hepatitis B and C among migrants in the EU/EEA. Stockholm: ECDC; 2016. 
Apéndice 2. Ejemplos de intervenciones realizadas en España en relación al cribado del VHC y vinculación de las personas diagnosticadas al seguimiento y tratamiento

\section{IMPLEMENTACIÓN DEL DIAGNÓSTICO EN UN SOLO PASO}

- Encuesta nacional de implementación del diagnóstico en un solo paso

Entre septiembre y octubre de 2019 , un equipo compuesto por personal de hepatología y microbiología realizó un estudio mediante encuesta con el objetivo de conocer el acceso a nuevas estrategias de diagnóstico en 161 centros hospitalarios en España. Respondieron 129 hospitales (tasa de respuesta 80\%). La implementación del diagnóstico en un solo paso aumentó del 31\% en 2017 al 89\% en 2019, al igual que el número de centros que utilizaba algún sistema de alerta para mejorar la continuidad asistencial, del 69\% al 86\%. Las medidas recomendadas por SEIMC, AEEH, SEPD, y AEHVE podrían haber contribuido al incremento de la implantación del diagnóstico en un solo paso (104).

\section{- Implementación del diagnóstico en un solo paso en Andalucía}

En 2018 se realizó un estudio en laboratorios responsables del diagnóstico del VHC en Andalucía para analizar las barreras al diagnóstico completo y el impacto de la implementación de estrategias de diagnóstico innovadoras. Se encontró que, durante 2016, casi la mitad de las personas con nuevos diagnósticos de infección por el VHCen el sur de España no habían sido derivadas para tratamiento tras una mediana de 71 días desde la fecha del diagnóstico. En 2018, tras implementar el diagnóstico en un paso, sólo el $17 \%$ de los pacientes no fueron evaluados para tratamiento, trasuna mediana de 52 días.

La implementación del diagnóstico en un paso contribuyó a mejorar la vinculación con el seguimiento y tratamiento de la infección por el VHC (105).

\section{ALERTAS EN LA HISTORIA CLÍNICA ELECTRÓNICA PARA RECORDAR EL CRIBADO DE VHC}

En mayo de 2019, La Dirección General de Salud Pública y la Gerencia Adjunta de Procesos Asistenciales de la Comunidad de Madrid incorporaron unas alertas en la Historia clínica Electrónica de Atención Primaria (AP-Madrid) para pacientes con VIH, sífilis, infección gonocócica, hepatitis $B$, hepatitis o hepatopatía que recuerdan que se debe realizar la prueba del VHC. Se añadió esta alerta a un total de 28.043 pacientes que tenían infección por el $\mathrm{VIH}$ y a 5.985 pacientes con el resto de patologías. Algunos de los Centros de Atención a Drogodependientes comparten el mismo sistema de información APMadrid. Además, se está trabajando en generar una alerta en pacientes con hipertransaminasemia, que se incluiría en los informes de resultados de los laboratorios de los hospitales. 


\section{CAMPAÑAS DE SENSIBILIZACIÓN SOBRE EL CRIBADO DEL VHC A LA POBLACIÓN GE NERAL}

\section{- Campañas de sensibilización en las Comunidades Autónomas de Madrid y Aragón}

Desde la Subdirección General de Promoción, Prevención y Educación para la Salud de la Comunidad de Madrid y la Dirección General de Asistencia Sanitaria de Aragón se han puesto en marcha campañas informativas de prevención y promoción del diagnóstico precoz de la hepatitis $C$ dirigidas a población general y colectivos más vulnerables $(106,107)$. Los materiales incluyen mensajes de información sobre la infección, su prevención y diagnóstico precoz. En la Comunidad de Madrid se difundió a todos los centros de salud de la Comunidad, hospitales públicos y privados, ONGs, centros de atención a personas con drogodependencias y otros recursos de la Consejería de Sanidad, ayuntamientos y asociaciones. En total se editaron 5.000 unidades de las que se han repartido 1.354 hasta diciembre de 2019 , el resto se difundirán en 2020 como apoyo a las acciones de sensibilización sobre el diagnóstico precoz en centros sanitarios y grupos prioritarios de población vulnerable.

\section{- Campañas de la Alianza para la Eliminación de las Hepatitis Víricas en España}

Desde la Alianza para la Eliminación de las Hepatitis Víricas en España (AEHVE) se promueven tres campañas anuales de promoción de la prueba de la hepatitis $C$ coincidiendo con la European Testing Week de mayo y noviembre y con motivo del Día Mundial de la hepatitis C. Se trata de campañas multicanal en medios de comunicación, redes sociales, publicidad exterior, cines y plataformas digitales de televisión. En 2019 se incluyó el testimonio de un actor, Carmelo Gómez, curado de hepatitis C, en un spot para cine que ha llegado a cerca de 1.150 .000 espectadores. Las campañas cuentan siempre con una landing page (https://unfinalfelizhepc.com/; http://www.erescris.es/) con información sobre exposiciones de riesgo y las pruebas, y un mensaje claro: la hepatitis $C$ se cura. La emisión de una de estas campañas durante la Testing Week de noviembre de 2018 hizo que la petición de la prueba de la hepatitis $C$ en los centros y puntos de Apoyo Positivo tan sólo en esa semana fuera el doble de todas las realizadas en todo el año. Sencillez y contundencia en el mensaje, formato atractivo y selección adecuada del canal y una cierta segmentación (por edad, aficiones, filiaciones...) son fundamentales cuando se quiere lograr un impacto elevado con recursos ajustados.

\section{- Campañas de la Federación Nacional de Enfermos y Trasplantados Hepáticos}

En los dos últimos años, la Federación Nacional de Enfermos y Trasplantados Hepáticos (FNETH) ha creado y participado de diversas acciones para sensibilizar sobre el diagnóstico precoz de la hepatitis C. A lo largo de 2019 se realizaron cuatro campañas. Para el Día Mundial de las Hepatitis, se lanzó 'Puedes ser tú', una campaña para promocionar el diagnóstico precoz del VHC, que tuvo hasta ochenta y ocho apariciones en medios de comunicación distintos y una audiencia estimada en casi 15 millones de personas. Otro de los ejemplos más recientes es 'Sé Magia', campaña que ha contado con la participación de destacadas personalidades del mundo del cine y que ha tenido repercusión en una decena de medios de comunicación con un impacto total estimado en 2,8 millones de impresiones. http://fneth.org/2019/11/28/puedes-ser-tu/; http://fneth.org/2019/11/04/spot-se-magia/ 


\section{CRIBADO Y VINCULACIÓN AL TRATAMIENTO DE PERSONAS PROCEDENTES DE PAÍSES CON ALTA PREVALENCIA DE INFECCIÓN POR EL VHC}

- Promoción del diagnóstico y tratamiento de la infección por el VHCen personas procedentes de Pakistán en Cataluña: Estudio HepC-link

En 2019 el IGTP, junto con la Unidad de Salud Internacional de Drassanes, el Hospital Vall d'Hebrón, el CEEISCAT y la ASPCAT, iniciaron el Estudio HepC-link (108), con un piloto para la sensibilización y promoción en el ámbito comunitario del cribado y tratamiento del VHC para personas procedentes de Pakistán, un país con alta prevalencia de hepatitis C. La captación se realizó en centros de formación, consulado y fiesta de la independencia, entre otros. Se les invitó a participar en sesiones educativas y realización de la prueba rápida de anticuerpos y la recogida de muestras de sangre seca para la detección del ARN-VHC. El equipo de medicina comunitaria contó con dos agentes de salud de Pakistán. Los resultados de las pruebas se facilitan en la unidad de salud internacional y se inicia el tratamiento del VHC, que es prescrito por especialistas de Hepatología.

\section{BÚSQUEDA DE PACIENTES CON DIAGNÓSTICO DE HEPATITIS C CON NECESIDAD DE VINCULACIÓN AL DIAGNÓSTICO COMPLETO Y TRATAMIENTOEN LOS REGISTROS SANITARIOS}

- Plan estratégico para la eliminación de la hepatitis C en Aragón

En el marco del Plan estratégico para la eliminación de la hepatitis Cen Aragón (107), en 2018 el Servicio de Salud Aragonés identificó a pacientes con diagnóstico de hepatitis $C$ y con necesidad de vinculación a tratamiento mediante la búsqueda activa en el Sistema de Información Microbiológica, registro de pacientes tratados con AAD y Base de Datos Única. Se analizaron las historias clínicas electrónicas de 3.123 pacientes que desde 2010 habían sido diagnosticados de hepatitis $C$, encontrando que el $31,6 \%$ era susceptible de ser derivado al servicio de hepatología para inicio de tratamiento. Se informó de estos pacientes a los centros de salud correspondientes para su incorporación al circuito de seguimiento y tratamiento diseñado en el Plan.

\section{- Propuesta de identificación de pacientes con hepatitis Cen Castilla y León}

En 2017, la Dirección General de Asistencia Sanitaria de Castilla y León diseñó una propuesta, basada en la experiencia del Hospital Universitario Río Hortega de Vallladolid, para identificar pacientes con infección por el VHC que no estuvieran en seguimiento por el Servicio de Digestivo o de Infecciosas y facilitarles el seguimiento. Se estableció una coordinación entre los servicios de Digestivo/Hepatología, Direcciones Asistenciales y Atención Primaria (AP). La búsqueda de pacientes se realizó por los Servicios de Admisión de cada centro con la colaboración de los Servicios Centrales de la Gerencia Regional de Salud. Se utilizaron la historia clínica electrónica de Atención Primaria, registros de carga viral de laboratorios, programa de citas de Digestivo/Hepatología y programa de Tarjeta Sanitaria. A los 
pacientes en los que se confirmó su ausencia de vinculación con Digestivo, fueron derivados para confirmación del diagnóstico y citación con Digestivo por el personal médico de Atención Primaria (109)

\section{- Servicio Navarro de Salud-Osasunbidea (SNS-O)}

En 2019 vivían en Navarra 3.850 personas con antecedentes conocidos de anticuerpos frente al VHC. Los servicios de Epidemiología y Microbiología del SNS-O han realizado una revisión de todos los análisis realizados en los últimos años, identificando a 1.307 personas con antecedentes de anticuerpos frente al VHC y en cuya historia clínica no constaba determinación posterior de carga viral. A cada médico de familia se le envió la relación de los pacientes de su cupo para informales y comprobar si tenían una infección activa. El $72 \%$ de los 1.084 pacientes ya citados y analizados no presentaron infección activa, sin embargo se detectó carga viral positiva en el $28 \%$ restante, que fue derivado para tratamiento (110).

\section{APOYO DE LAS ORGANIZACIONES SOCIALES DELÁMBITO DE LA PREVENCIÓN DEL VIH Y OTRAS ITS}

\section{- Programa de acompañamiento terapéutico de CESIDA}

El programa de acompañamiento terapéutico de CESIDA tiene como fin facilitar la adherencia al tratamiento de la hepatitis $C$ a pacientes vulnerables como personas usuarias de drogas, internas en centros penitenciarios, con patología psiquiátrica concomitante o personas sin hogar. El programa consiste en apoyar a la persona durante el proceso terapéutico, mediante acompañamiento a las visitas médicas y farmacia, llamadas telefónicas, tratamiento directamente observado si procede, y apoyo social y jurídico, en coordinación entre las ONG y los servicios de salud. Hasta el momento se han conseguido unas tasas de RVS similares a la población general. El programa fue iniciado por la asociación ACAVIH de Alicante y durante 2018 y 2019 se ha extendido a las ciudades de Murcia y Valencia.

\section{CRIBADOY VINCULACIÓN AL TRATAMIENTO DE PERSONAS QUE ACUDEN A CENTROS DE ATENCIÓN A PERSONAS CON DROGODEPENDENCIAS}

A) Realización de pruebas en los centros de atención a drogodependencias y facilitación de la adherencia al tratamiento

- Diagnóstico de VIH y VHC en pacientes atendidos en centros de atención de drogodependencias de Córdoba. Proyecto HIVDEN-C

En los centros de atención de drogodependencias de Córdoba en 2019 se realizó un estudio para detectar a las personas con infección por el VHCy el VIH para su posterior inclusión en programas de tratamiento y seguimiento. Se derivaron 621 personas para la realización de serología y diagnóstico en un solo paso en el Hospital de Día de Enfermedades Infecciosas del Hospital Universitario Reina Sofía, 
de las que un 25,4\% no acudió. De las 463 personas usuarias de drogas que se realizaron las pruebas, un 6,3\% tenía infección activa por el VHC. Se planteó la necesidad del uso de pruebas rápidas en los mismos centros de drogodependencias y una derivación más ágil a la unidad de infecciosas para mejorar el proceso diagnóstico completo.

\section{- Proyecto HepCare Europe Spain en Sevilla}

El proyecto HepCare Europe (111), desarrollado en España desde el Servicio de Infecciosas del Hospital Virgen de Valme de Sevilla (112), plantea el desarrollo de un modelo integrado de cuidados con poblaciones vulnerables que necesitan a poyo para el acceso a la asistencia y tratamiento de la hepatitis C. En el subproyecto HepCheck, entre 2017 y 2019, un equipo sanitario se desplazó a los centros de tratamiento de adicciones, comunidades terapéuticas y ONG, para detectar marcadores de infección por el VHC en sangre o saliva. En el subproyecto HepLink, se facilitó acceso directo a la asistencia especializada a los pacientes con ARN-VHC. De 897 personas invitadas al cribado, 636 aceptaron, de las que un $17 \%$ ( $n=108$ ) tenía infección activa por el VHC. De estos 108 pacientes, el 38\% alcanzó RVS12 y el $38 \%$ se perdió en el seguimiento, el resto sigue en tratamiento. La facilitación del diagnóstico debe ir acompañado de otras medidas para la vinculación al seguimiento.

En 2017 el Centro Municipal de Intervención en Drogodependencias (CEMID) y el Hospital de Écija en la provincia de Sevilla comenzaron a trabajar en el proyecto HepCare. Como parte del proyecto, se realiza prueba rápida oral de anticuerpos, valoración de fibrosis en el mismo centro, derivación al servicio de Digestivo del Hospital de Écija, educación sanitaria para prevenir la reinfección, y facilitación de la recogida de medicación en el hospital más cercano. Se encontraron puntos de mejora, sobre todo en la derivación a digestivo, que se han ido trabajando con éxito a lo largo de los tres años de implementación del proyecto.

\section{- Modelo de cribado y tratamiento de la hepatitis $\mathrm{C}$ en un centro de reducción de daños en Barcelona}

En el Centro de Reducción de Daños La Mina en Sant Adrià del Besós, junto al Hospital Clínic de Barcelona, se ha pilotado un modelo descentralizado de consulta de hepatología (113). Se realizan talleres de educación sanitaria sobre el VHC y se ofrece el diagnóstico mediante prueba rápida de anticuerpos y de ARN del VHCen sangre capilar. Tras la valoración inmediata del paciente y evaluación de la fibrosis hepática, el personal especialista prescribe el tratamiento, que es dispensado por el personal de enfermería en el propio centro. En 2019 se incluyeron 610 personas usuarias, de las que 323 aceptaron el cribado, presentando infección activa 189 (58\%) personas. De éstas, el 70\% iniciaron tratamiento antiviral dentro del programa del centro. Los resultados preliminares mostraron más del $80 \%$ de adherencia al tratamiento en la mayoría de los pacientes y una RVS12 del $80 \%$, siendo la reinfección el motivo de la mayor parte de los casos sin respuesta virológica. Este modelo multidisciplinar centrado en el paciente, muestra que el diagnóstico en un solo paso y el acceso rápido e "in situ" al tratamiento permite atender de manera más efectiva a poblaciones vulnerables como las personas con consumo activo de drogas. También pone de manifiesto la relevancia de mantener un cribado periódico para el diagnóstico de la reinfección, así como intervenciones educativas y preventivas para reducir la transmisión del VHC. 


\section{- Proyecto de eliminación de hepatitis $C$ en pacientes atendidos en centros de asistencia ambulatoria de drogodependientes de Castilla y León}

En el marco del VII Plan regional sobre drogas de Castilla y León (2017-2021), la Gerencia Regional de Salud, a través de la Dirección General de Asistencia Sanitaria, y la Gerencia de Servicios Sociales, a través del Comisionado Regional para la Droga, iniciaron, en octubre de 2019, un proyecto de eliminación de hepatitis $C$ en pacientes atendidos en centros específicos de asistencia ambulatoria a drogodependientes de Valladolid (dos CAD y dos centros de día). En estos centros se ofrece la detección del VHC a todos los pacientes atendidos que no se hayan realizado la prueba en el último año. EI personal de estos centros traslada las muestras hasta el Servicio de Microbiología del Hospital Universitario Rio Hortega, que envía los resultados al centro específico de asistencia a drogodependientes y al centro de salud, derivando los casos positivos a la unidad de hepatología de referencia, donde se realiza el diagnóstico confirmatorio y se instaura tratamiento en caso necesario. El tratamiento es recogido por el paciente o persona delegada en la farmacia hospitalaria, o por el personal del centro de asistencia a drogodependientes si requiere tratamiento supervisado. El seguimiento terapéutico se realiza tanto desde las unidades de hepatología como desde los centros de asistencia a drogodependientes, informándose de todo ello al centro de salud de referencia. Una vez pilotados sus resultados, el proyecto pretende extenderse al resto de provincias de Castilla y León.

- Atención a las personas con hepatitis C en el Centro de Reducción de Riesgos y Daños de Bizkaisida, Bilbao

En 2018, en el Centro de reducción de Riesgos y Daños y de Bizkaisida, en Bilbao, se puso en marcha una estrategia de abordaje de la hepatitis $C$ en personas que se inyectan drogas y que están en situación de grave exclusión social. Se realizan talleres de educación para la salud y se forman a las personas usuarias como agentes de salud, donde sus experiencias contribuyen a la sensibilización sobre el avance del tratamiento de la hepatitis $C$, y al conocimiento de sus derechos y oportunidades. Se ofrece la realización de la prueba rápida de anticuerpos en el mismo centro. En primer lugar se derivaba y se acompañaba a Atención Primaria para la confirmación y posterior derivación, pero los resultados fueron muy limitados. A partir de octubre de 2019 se les deriva directamente al H.U. de Basurto, reduciendo el tiempo de espera. Esta experiencia muestra la utilidad del cribado en el entorno de la persona, así como del acompañamiento y seguimiento en el acceso y la adherencia al tratamiento de la hepatitis Cen esta población vulnerable.

\section{B) Coordinación interdisciplinar}

\section{- Seguimiento del VHC en personas usuarias de drogas en Murcia}

El Centro de Atención a Drogodependencias de Murcia es centro de referencia para tres áreas de salud y tres hospitales. Para mejorar la detección y tratamiento del VHC en las personas atendidas en este centro, se ha establecido una coordinación entre profesionales sanitarias/os de los servicios de infecciosas de cada hospital, Instituciones Penitenciarias y CAD, con reuniones y comunicación periódicas. El tratamiento directamente observado, el acceso inmediato a la atención especializada y la facilitación de los fármacos antivirales al equipo del CAD posibilitan un cuidado más efectivo de estos pacientes (114). 
- Programa de atención multidisciplinar para pacientes con adicciones e infección por el VHC en el área litoral de Barcelona: Programa PAM ADIC-C.

En junio de 2018 se creó el Programa de Atención Multidisciplinar para pacientes con adicciones y VHC en el Hospital del Mar, dirigido a pacientes atendidos en los Centros de Atención y Seguimiento (CAS) de drogodependencias y centros de reducción de daños de su área de referencia. De manera coordinada, personal de diferentes servicios hospitalarios (psiquiatría-adicciones, farmacia, hepatología) trabajan en el CAS Barceloneta. Se realiza cribado del VHC en los diferentes centros y se derivan de forma directa y en menos de un mes a la visita en el CAS Barceloneta. Los pacientes acuden acompañados por un educador social del centro de origen quien tras la primera visita se encarga de depositar la medicación en dicho centro desde donde se dispensa. En la primera visita en CAS Barceloneta se lleva a cabo la evaluación completa del paciente, de la medicación concomitante, se realiza analítica y elastografía basal, y se inicia el tratamiento. Hasta el momento, han iniciado tratamiento 74 pacientes de los cuales únicamente dos no lo han completado por haberse perdido en el seguimiento. La mediana de adherencia al tratamiento es del $100 \%$ y la RVS (mITT) del 96, $7 \%$. Por ahora no se ha detectado ningún caso de reinfección.

\section{C) Diagnóstico completo inicio del tratamiento en el mismo día}

- Centro de Atención y Seguimiento de Drogodependencias de Nou Barris

En el CAS de Nou Barris, tras la detección de un 7\% de personas usuarias con infección activa por el VHC, se identificaron puntos de mejora en el circuito convencional de diagnóstico, seguimiento y derivación del CAS al hospital de referencia. Para mejorar el acceso y garantizar el tratamiento, se ha adaptado el circuito asistencial a las características del colectivo, que implica el diagnóstico en un solo paso, asignación de cita rápida, y estudio y tratamiento en un mismo día.

- Iniciativas para el cuidado de las personas con hepatitis $C$ en el Centro de Tratamiento Ambulatorio ANTARIS en Dos Hermanas, Sevilla

El Centro de Tratamiento Ambulatorio (CTA) ANTARIS ha trabajado junto al Hospital Virgen de Valme en varias iniciativas para adaptar los recursos a las diferentes necesidades de las personas atendidas en el centro. Las actividades son cita telefónica directa en el Servicio de Infecciosas, consulta presencial en el mismo CTA del equipo de Infecciosas para detección de ARN del VHC, cita para valoración de fibrosis e inicio de tratamiento en el mismo día y visitas a domicilio o en el CTA del equipo de Infecciosas y Farmacia para diagnóstico e inicio de tratamiento, entre otras. Los recursos son utilizados en función de las necesidades de cada paciente.

\section{D) Estudios sobre el uso de muestras de sangre seca en centros de atención a drogodependencias}

- Estudio HepCdetect en centros de atención a personas con drogodependencias en Cataluña

En 2016, el Servicio de Microbiología del Hospital Germans Trias i Pujol (IGPT) realizó un estudio de validación de la prueba de ARN del VHC en muestra de sangre seca en cuatrocentros de reducción de 
daños en la provincia de Barcelona, en colaboración con el Centro de Estudios Epidemiológicos sobre las ITSy sida de Cataluña (CEEISCAT) y la Agencia de Salud Pública de Cataluña (ASPCAT). La prevalencia de infección activa de VHC en las 410 personas usuarias de drogas fue del 58,5\%, y un $35,8 \%$ de ellas no conocía su estado previamente. La sensibilidad y especificidad de la detección directa del ARN en sangre seca fue similar al diagnóstico en dos pasos (prueba rápida de anticuerpos seguida del estudio del ARN en plasma), concluyendo que puede mejorar las tasas de diagnóstico de infección activa en las personas que se inyectan drogas (91).

En 2018 se evaluó en el centro de consumo supervisado de drogas de Sant Adrià del Besòs la validez de dos pruebas alternativas para detectar el ARN del VHC en sangre obtenida por punción dactilar, una prueba realizada en el punto de atención en sangre fresca y otra basada en sangre seca analizada en el laboratorio (115). El estudio mostró una alta sensibilidad y especificidad de ambas pruebas, reportando una prevalencia de infección activa del 63\%. El diagnóstico simplificado y la entrega de resultados en el mismo centro el acceso de este colectivo vulnerable al diagnóstico, y han abierto la posibilidad de realizar también el tratamiento del VHC en este centro (113).

- Estudio piloto del uso de gota de sangre seca para diagnóstico en un solo paso de la hepatitis Cen un Centro de Atención de Adicciones en Granada

El Hospital Universitario de San Cecilio de Granada estudió la validez de una prueba de detección de anticuerpos y ARN del VHC en muestras de sangre seca en el Centro de Atención de Adicciones de la zona norte de Granada COIS Norte. Se encontró una correlación del 96,5\% para la detección de anticuerpos y del $100 \%$ para la de viremia. Los valores de viremia fueron cuantitativamente inferiores en sangre seca que en plasma, permitiendo aun así identificar pacientes que no acuden a Atención Primaria. Se encontró una prevalencia de infección activa del $21 \%$ en los 57 pacientes analizados, de los que sin embargo solo el $25 \%$ acudió posteriormente a atención especializada. Esto pone de relieve la importancia de la vinculación al seguimiento y tratamiento tras el diagnóstico (116).

\section{CRIBADO Y VINCULACIÓN AL TRATAMIENTO DE PERSONAS INTERNAS EN CENTROS PENITENCIARIOS}

\section{- Programa de eliminación del VHC en el centro penitenciario "EI Dueso" en Cantabria}

Entre 2016 y 2017, se realizó una intervención multidisciplinar en el centro penitenciario El Dueso en Cantabria (117), con el fin de diagnosticar y tratar a todas las personas con infección por el VHC con permanencia en el centro superior a treinta días. Participó el 99,5\% de las personas internas, encontrando una prevalencia de viremia del 10,2\%. Se estableció un programa de telemedicina con reuniones virtuales para realizar el seguimiento de los pacientes desde el hospital. Se consiguió una RVS12 del 96,9\%, no detectándose viremia ni reinfección en ninguna de las personas que permanecían internas al final del estudio. 


\section{BIBLIOGRAFÍA}

1. Plan estratégico para el abordaje de la hepatitis C en el Sistema Nacional de Salud. Ministerio de Sanidad, Servicios Sociales e $2015 . \quad$ Disponible en: https://www.msssi.gob.es/ciudadanos/enfLesiones/enfTransmisibles/hepatitisC/PlanEstrategicoHEPATITISC /docs/plan_estrategico_hepatitis_C.pdf

2. Ministerio de Sanidad. El Ministerio de Sanidad reitera su compromiso de avanzar hacia la eliminación de la hepatitis C. Notas de prensa. 2019. Disponible en: https://www.mscbs.gob.es/gabinete/notasPrensa.do?id=4672

3. Preval encia de las infecciones VIH y hepatitis C en Instituciones Penitenciarias. Año 2019. Subdirección General de Coordinación de Sanidad Penitenciaria. Área de Salud Pública; 2020. Disponible en: http://www.institucion penitenciaria.es/web/export/sites/default/datos/descargables/saludpublica/Prevale ncia_VIH_y_VHC_en_IIPP_2019.pdf

4. Evolución de la co-infección por Virus Hepatitis C de las personas VIH-positivas de la cohorte CoRIS: 20042018. Informe elaborado por la Unidad de Coordinación de la cohorte CoRIS, Centro Nacional de Epidemiología, Instituto de Salud Carlos III; 2020.

5. Berenguer J, Jarrín I, Pérez-Latorre L, Hontañón V, Vivancos MJ, Navarro J, et al. Human Immunodeficiency Virus/Hepatits C Vi rus Coinfection in Spain: Elimination Is Feasible, but the Burden of Residual Cirrhosis Will Be Significant. Open Forum Infect Dis. 2018;5(1):ofx258.

6. Grupo de trabajo del estudio de prevalencia de la infección por hepatitis $C$ en población general en España; 2017-2018. Resultados del $2^{\circ}$ Estudio de Seroprevalencia en España (2017-2018). Ministerio de Sanidad, Consumo y Bienestar Social; 2019. Disponible en: https://www.mscbs.gob.es/ciudadanos/enfLesiones/enfTransmisibles/sida/docs/INFORME_INFECCION_VHC ESPANA2019.pdf

7. Organización Mundial de la Salud. Es trategia mundial del sector de la salud contra las hepatitis víricas 20162021. Hacia el fin de las hepatitis víricas. Ginebra: OMS; 2016. Disponible en: http://apps.who.int/iris/bitstream/10665/250578/1/WHO-HIV-2016.06-spa.pdf?ua=1

8. WHO Regional Office for Europe. Action plan for the health sector response to viral hepatitis in the WHO European Region. WHO; 2017. Disponible en: http://www.euro.who.int/en/health-topics/communicablediseases/hepatitis/publications/2017/action-plan-for-the-health-sector-respons e-to-viral-hepatitis-in-thewho-european-region-2017

9. Organización Mundial de la Salud. Guidelines on hepatitis B and C testing. Ginebra: OMS; 2017. Disponible en: http://www.who.int/hepatitis/publications/guidelines-hepatitis-c-b-testing/en/

10. European Centre for Disease Prevention and Control. Public health guidance on HIV, hepa titis B and C testing in the EU/EEA - An integrated approach. Stockholm: ECDC; 2018. Disponible en: https://www.ecdc.europa.eu/sites/default/files/documents/hiv-hep-testing-guidance_0.pdf

11. Institut für Qualität und Wirtschaftlichkeit im Gesundheitswes en. Screening for hepatitis C. Extract of final report S16-04. Köln: IQWiG; 2018. Disponible en: S16-04_Screening-for-hepatitis-C_Extract-of-finalreport_V1-0.pdf

12. Cana dian Task Force on Preventive Hea th Ca re. Recommendations on hepatitis C screening for adults. CMAJ. 2017;189(16):E594-604. Disponible en: https://www.cmaj.ca/content/189/16/E594

13. National Institute for Health and Ca re Excellence. Offering and providing hepati tis $B$ and $C$ tes ts and hepatitis $B$ vaccination. NICE Pathways. NICE; 2017. Disponible en: hepatitis-b-and-c-testing-offering-and-providinghepatitis-b-and-c-tests-and-hepatitis-b-vaccination.pdf

14. Public Health England. Hepatitis $C$ in England 2019. London; 2019. Disponible en: https://assets.publishing.service.gov.uk/government/uploads/system/uploads/atta chment_data/file/79827 0/HCV_in-England_2019.pdf

15. Haute Autorité de Santé. Hépatite C: prise en charge simplifiée chez l'adulte. 2019. Disponible en: https://www.has-sante.fr/jcms/c_2911891/fr/hepatite-c-prise-en-charge-simplifiee-chez-I-adulte\#toc_1_5

16. Department of Health. Hepa titis C Screening (NCEC National Clinical Guideline No. 15). Dublin: Department of Health;2017. Disponible en: https://www.gov.ie/en/collection/e4bb9d-hepatitis-c-screening/

17. Direção-Geral da Saúde. Avaliação Diagnóstica da Infeção por Vírus da Hepatite C. Lis boa; 2017. Report No.: Norma nº27/2017 de 28/12/2017. 
18. US Preventive Services Task Force. Draft Recommendation Statement: Hepatitis C Virus Infection in Adolescents and Adults: Screening. USPSTF Recommendations. 2019. Disponible en: https://www.uspreventiveservicestaskforce.org/Page/Document/draft-recommendationstatement/hepatitis-c-screening1

19. The Scottish Government. Sexual Health and Blood Borne Virus Framework. 2015-2020 Update. Disponible en: $\quad$ https://www.gov.scot/publications/sexual-health-blood-borne-virus-framework-2015-2020update/pages/7/

20. Department of Health. Fifth National Hepatitis C Strategy. Australian Government; 2018. Dis ponible en: https://www.health.gov.au/internet/main/publishing.nsf/Content/ohp-bbvs-1//\$File/Hep-C-Fifth-NatStrategy-2018-22.pdf

21. Gómez-Escolar Viejo L, García Herola A, Sáez Lloret I, Sánchez Ruano F, Clemente Paulino I, Quílez Ivorra C, et al. Screening of hepatitis C virus infection in adult general population in Spain. Eur J Ga stroenterol Hepatol. 2018;30(9):1077-81.

22. Servicio de Epidemiología. Avance de resultados de la V Encuesta de Serovigilancia de la hepatitis C. Comunidad de Madrid. Año 2015. Boletín Epidemiológico de la Comunidad de Madrid 2017. Consejería de Sanidad; 2017. Disponible en:www.madrid.org/boletinepidemiologico/

23. Secretaria de Salut Pública. Plan de prevención y control de la hepatitis C en Cataluña. Generalitat de Catalunya; 2018.2 Disponible en: http://salutpublica.gencat.cat/web/.content/minisite/aspcat/vigilancia_salut_publica/vih-sidaits/04_Hepatitis_viriques/Plan-Hepatitis-Definitivo_C_DEF_ES.pdf

24. Bruguera M, Forns X. Hepatitis C en España. Med Clin. 127(3):113-7.

25. Barranco Boada M, Vicente Martínez E, García-Fulgueiras A. Vigilancia epidemiológica de la hepatitis C. Nuevos diagnósticos en la Región de Murcia. Actualización año 2017. Murcia: Consejería de Salud; 2019. (Informes epidemiológicos). Report No.: 3/19.

26. Pérez-Álvarez R, García-Samaniego J, Solá R, Pérez-López R, Bárcena R, Planas R, et al. Acute hepatitis C in Spain: a retrospective study of 131 cases. Rev Esp Enferm Dig. 2012;104(1):21-8.

27. Pineda JAP, Neukam K. Hepatitis aguda $C$ en va rones homosexuales infectados por VIH: ¿ una segunda oleada de coinfección por VIH y VHC? Enferm Infecc Microbiol Clin. 2015;33(1):1-2.

28. Cabello A, Cano R, Prieto-Pérez R, Pérez-Tanoira J, Beni to N, Rallón N, et al. Hepatitis C aguda en hombres que tienen sexo con hombres con VIH. Una epi demia en a uge. Enferm Infecc Microbiol Clin. 2019;37(Espec Cong 1):84.

29. Aaron S, McMahon JM, Milano D, Torres L, Clatts M, Tortu S, et al. Intranasal transmission of hepatitis C virus: virological and clinical evidence. Clin Infect Dis. 2008;47(7):931-4.

30. Schei nmann R, Hagan H, Lelutiu-Weinberger C, Stern R, Des Jarl ais DC, Flom PL, et al. Non-injection drug use and Hepatitis C Virus: a systematic review. Drug Alcohol Depend. 2007;89(1):1-12.

31. Martínez-Rebollar M, La rrousse M, Calvo M, Muñoz A, González A, Loncà M, et al. Estado actual de la hepatitis aguda C. Enferm Infecc Microbiol Clin. 2011;29(3):210-5.

32. Martínez-Bauer E, Forns $X$, Armel les M, Planas R, Solà R, Vergara M, et al. Hos pital admission is a relevant source of hepatitis C virus a cquisition in Spain. J Hepa tol. 2008;48(1):20-7.

33. Tavos chi L, Mason L, Petriti U, Bunge E, Vel dhuijzen I, Duffell E. Hepatitis B and C among healthcare workers and patient groups at increased risk of iatrogenic transmission in the European Union/European Economic Area.J Hosp Infect. 2019;102(4):359-68.

34. García-Agudo R, Aoufi-Rabih S, Barril-Cuadrado G. Estudio multicéntrico español SHECTS: situación hepática de los pacientes con hepatitis crónica por el VHC en tratamiento sustitutivo renal con hemodiálisis. Nefrología. 2013;33(2):188-95.

35. Averbukh LD, Wu GY. Highlights for Dental Care as a Hepatitis C RiskFactor: A Review of Literature. J Clin Transl Hepatol. 2019;7(4):346-51.

36. Castro Ferreiro $\mathrm{M}$, Hermida Prieto $\mathrm{M}$, Diz Dios $\mathrm{P}$. Transmisión de la hepatitis $\mathrm{C}$ esporádica en el ámbito odontológico. Med Clin. 2004;123(7):271-5.

37. Sociedad Es pañola de Transfusión Sangínea y Terapia Cel ular. Guía sobre la transfusión de componentes sanguíneos y derivados plasmáticos. 2015. Disponible en: http://www.sets.es/index.php/cursos/bibliotecavirtual/guias-y-publicaciones-sets/guias-y-publicaciones-acceso-abierto/413-guiatransfusio-n-5-edicion2015/file 
38. Ministerio de Sanidad, Servicios Sociales e Igualdad. Guía de Bioseguridad para los profesionales sanitarios. MSSSI; 2015.2 Disponible en: http://www.mscbs.gob.es/ciudadanos/enfLesiones/enfTransmisibles/hepatitisC/informacion/docs/Guia_Bio seguridad_profesionales_sanitarios.pdf.

39. Jafari S, Copes R, Baharlou S, Etminan M, Buxton J. Tattooing and the risk of transmission of hepatitis C: a sys tematic review and meta-analysis. Int J Infect Dis. 2010;14(11):e928-940.

40. Tohme RA, Holmberg SD. Transmission of hepatitis C virus infection through tattooing and piercing: a critical review. Clin Infect Dis. 2012;54(8):1167-78.

41. European Centre for Disease Prevention and Control. Hepatitis B and C epidemiology in selected population groups in the EU/EEA. Stockholm: ECDC;2018. Disponible en: https://www.ecdc.europa.eu/en/publicationsdata/hepatitis-b-and-c-epidemiology-selected-population-groups-eueea

42. Mariano A, Mele A, Tosti ME, Parlato A, Gallo G, Ragni P, et al. Role of beauty treatment in the spread of parenterally transmitted hepatitis viruses in Italy. J Med Virol. 2004;74(2):216-20.

43. Amodio E, Di Benedetto MA, Gennaro L, Maida CM, Romano N. Knowledge, attitudes and risk of HIV, HBV and HCV infections in hairdressers of Palermo city (South Italy). Eur J Public Health. 2010;20(4):433-7.

44. Observatorio Es pañol de las Drogas y las Adicciones. Alcohol, tabaco y drogas ilegales en España. Informe 2019. Ministerio de Sanidad, Consumo y Bienestar Social; 2019. Disponible en: http://www.pnsd.mscbs.gob.es/profesionales/sistemasInformacion/informesEs tadisticas/pdf/2019OEDAINFORME.pdf

45. Roncero C, Littlewood R, Vega P, Martinez-Raga J, Torrens M. Chronic hepatitis C and individuals with a history of injecting drugs in Spain: population assessment, challenges for successful treatment. Eur J Gastroenterol Hepatol . 2017;29:629-33.

46. Del ega ción del Gobierno para el Plan Nacional sobre Drogas. Encuesta sobre alcohol y otras drogas en España (EDADES), 1995-2017. Ministerio de Sanidad, Consumo y Bienestar Social; 2019. Disponible en: http://www.pnsd.mscbs.gob.es/profesionales/sistemasInformacion/sistemalnformacion/pdf/EDADES_2017 Informe.pdf

47. Fanciulli C, Berenguer J, Busca C, del Campo S, Domínguez L, Navarro J, et al. HIV/HCV coinfection in Spain: trouble will soon be over. Enferm Infecc Microbiol Clin. 2019;37(Especial Congreso3):6-7.

48. Centro Nacional de Epidemiología, Plan Nacional sobre el Sida. Encuesta Hospitalaria de pacientes con infección por el VIH. Resulta dos 2018. Análisis de la evolución 2003-2018. Instituto de Salud Carlos III. Madrid; 2019.

49. Berenguer J, Gil-Martin Á, Jarrin I, Montes ML, Domínguez L, Aldámiz-Echevarría T, et al. Reinfection by hepatitis $C$ virus following effective all-oral direct-acting antiviral drug therapy in HIV/hepatitis $C$ virus coinfected individuals. AIDS. 2019;33(4):685-9.

50. Encuesta europea on-line para hombres que tienen sexo con hombres (EMIS-2017): resultados en España. Ministerio de Sanidad; 2020.

51. Fernández-Dávila $P$, Folch $C$, Ferrer $L$, Soriano R, Diez $M$, Casabona J. Hepatitis $C$ virus infection and its relationship to certain sexual practices in men-who-have-sex-with-men in Spain: Results from the European MSM internet survey (EMIS). Enferm Infecc Microbiol Clin. 2015;33(5):303-10.

52. The EMIS Network. EMIS-2017 - The European Men-Who-Have-Sex-With-Men Internet Survey. Key findings from 50 countries. Stockholm: European Centre for Disease Prevention and Control; 2019. Disponible en: https://www.esticom.eu/Webs/ESTICOM/EN/emis-2017/surveyreport/EMIS_2017_REPORT_ECDC.pdf;jsessionid=9A97F1EF4AF3F9166D625BF1A1AF0625.1_cid390?_blob $=$ publicationFile $\& v=1$

53. Fanciulli C, Berenguer J, Busca C, Vivancos M, Domínguez L, Nava rro J, et al. HIV/HCV coinfection in Spain: moving fast towards elimination. $X$ Congreso Nacional GeSIDA; 2018 nov; Madrid. Disponible en: http://2018.congresogesida.es/images/site/ponencias/Dia3_Jueves8/OR-09_OR-16_Auditorio/OR-14.pdf

54. Laza rus JV, Bromberg DJ, Del Amo J, Norgaard O, García-Samaniego J, Casellas A, et al. Hepatitis C prevalence among the migrant population in Spain: A systema tic review and meta-analysis. Enferm Infecc Microbiol Clin. 2019;37(4):222-230.

55. European Centre for Disease Prevention and Control. Assessing the burden of key infectious diseases affecting migrant populations in the EU/EEA. Stockholm: ECDC; 2014. Disponible en: 
https://www.ecdc.europa.eu/sites/default/files/media/en/publications/Publications/assessing-burdendisease-migrant-populations.pdf

56. European Centre for Disease Prevention and Control. Epidemiological assessment of hepatitis B and C a mong migrants in the EU/EEA. Stockholm: ECDC; 2016. Disponible en: https://www.ecdc.europa.eu/sites/portal/files/media/en/publications/Publications/epidemiologicalas s essment-hepatitis-B-and-C-among-migrants-EU-EEA.pdf

57. Centro Nacional de Epidemiología. Vigilancia epidemiológica de la Hepatitis C en Es paña, 2018. Insti tuto de Salud Carlos III; 2019.

58. Juanbeltz R, Pérez-García A, Aguinaga A, Martínez-Baz I, Casado I, Burgui C, et al. Progress in the elimination of hepatitis C virus infection: A population-based cohort study in Spain. PLoS ONE. 2018;13(12):e0208554.

59. Al ejos B, Aranburu M, Del Romero J, García F, Antela A, Cervero M, et al. Evolución de la prevalencia de anticuerpos positivos frente a VHC de las personas VIH-positivas de la cohorte CoRIS: 2004-2018. Reunión bi anual de la Sociedad Es pañola Interdisciplinaria del Sida (SEISIDA); 2020 a br 2; Insti tuto de Salud Carlos III, Madrid.

60. Enfermedades de declaración obligatoria en Institu ciones Penitenciarias. Año 2018. Subdirección General de Coordinación de Sanidad Penitenciaria; 2019. Disponible en: http://www.institucionpenitenciaria.es/web/export/sites/default/datos/descargables/saludpublica/Enferme dades_Declaracion_Obligatoria_2018.pdf

61. Mauss S, Pol S, Buti M, Duffell E, Gore C, Lazarus JV, et al. Late presentation of chronic viral hepatitis for medical care: a consensus definition. BMC Med. 2017;15(1):92.

62. Lazarus JV, Picchio C, Dillon JF, Rockstroh JK, Weis N, Buti M. Too many people with viral hepatitis are diagnosed late - with dire consequences. Nat Rev Gastroenterol Hepa tol. 2019;16(8):451-2.

63. Picchio C, Balanza N, Lens S, Arenas J, Gomez A, Turnes J, et al. Description of viral hepatitis patients and ass ociated risk factors of late presentation to ca re in Spain: a country with unrestricted access to treatment. The Liver Meeting, AASLD. Boston, 2019.

64. The College of Family Physicians of Canada, Public Health Agency of Canada. Primary Care Ma nagement of Chronic Hepatitis C. $2009 . \quad$ Disponible en: https://www.cfpc.ca/uploadedFiles/Resources/Resource_Items/HEP_C_Guide_eng_2.pdf

65. Schillie S, Wester C, Osborne M, Wesolowski L, Ryerson A. CDC Recommendations for Hepatitis C Screening Among Adul ts - United States, 2020. MMWRRecomm Rep. 2020;69(No. RR-2):1-17.

66. Comisión para reducir las desigualdades sociales en salud en Es paña. Ava nzando hacia la equidad. Propuestas de pol íticas e intervenciones para reducir las desigualdades sociales en salud en España. Ministerio de Sanidad, Servicios Sociales e Igualdad. Madrid; 2015. Disponible en: https://www.mscbs.gob.es/profesionales/saludPublica/prevPromocion/promocion/desigualdadSalud/docs/ Propuesta_Politicas_Reducir_Desigualdades.pdf

67. Velasco Arias S. Recomendaciones para la práctica del enfoque de género en programas de salud. 2008. Disponible

en: https://www.mscbs.gob.es/organizacion/sns/planCalidadSNS/pdf/equidad/recomendVelasco2008.pdf

68. Abrai ra García L, Ca sás Martínez A, García Sierra A, Guillán Pavón B, Jorge Sánchez R. Guía de práctica clínica. Hepatitis C. Consellería de Sanidad y Servicio Gallejo de Salud, Xunta de Galicia; 2014. Disponible en: https://portal.guiasalud.es/wp-content/uploads/2018/12/GPC_531_Hepatitis_C_actualizacion12.pdf

69. WestbrookR, Dus heiko G. Natural history of hepatitis C. J Hepa tol. 2014;61(1 Suppl):S58-68.

70. Thein $\mathrm{H}-\mathrm{H}, \mathrm{Yi}$ Q, Dore GJ, Krahn MD. Es timation of stage-specific fibrosis progression rates in chronic hepatitis C virus infection: a meta-analysis and meta-regression. Hepatology. 2008;48(2):418-31.

71. Al billos Martinez A, Caña da Merino J, Mol ero García J, Pérez Cachafeiro S, Pérez Escanilla F, Si món Marco M, et al. Consenso de recomendaciones para el diagnóstico precoz, la prevención y la a tención clínica de la Hepatitis C en Atención Primaria. AEEH, SEMERGEN, SemFYC, SEMG; 2017. Disponible en: https://www.semfyc.es/biblioteca/consenso-diagnostico-prevencion-hepatitis-c-atencion-primaria/

72. Organización Mundial de la Salud. Guidelines for the care and treatment of persons diagnosed with chronic hepatitis C virus infection. Ginebra: OMS; 2018. Disponible en: https://www.who.int/hepatitis/publications/hepatitis-c-guidelines-2018/en/

73. Real Decreto 412/1996, de 1 de marzo, por el que se esta blecen los protocolos obligatorios de es tudio de los dona ntes y usuarios relacionados con las técnicas de reproducción humana a sistida y se regul a la creación y 
organización del Registro Nacional de Donantes de Gametos y Preembriones con fines de reproducción humana. BOE mar 23, 1996. Disponible en: https://www.boe.es/buscar/act.php?id=BOE-A-1996-6644

74. Real Decreto $1088 / 2005$, de 16 de septi embre, por el que se esta blecen los requisitos técnicos y condiciones mínimas de la hemodonación y de los centros y servicios de transfusión. BOE sep 20, 2005. Disponible en: https://www.boe.es/buscar/pdf/2005/BOE-A-2005-15514-consolidado.pdf

75. Real Decreto $1723 / 2012$, de 28 de diciembre, por el que se regulan las actividades de obtención, utilización clínica y coordinación territorial de los órganos humanos destinados al trasplante y se establecen requisitos de calidad y seguridad. BOE dic 29, 2012. Disponible en: http://www.coordinaciontrasplantes.org/images/bibliografia/20-02.pdf

76. Real Decreto-ley $9 / 2014$, de 4 de julio, por el que se establecen las normas de calidad y seguridad para la donación, la obtención, la evaluación, el procesamiento, la preservación, el a lmacenamiento y la distribución de células y tejidos humanos y se aprueban las normas de coordinación y funcionamiento para su uso en humanos. BOE jul 5, 2014. Disponible en: https://www.boe.es/buscar/doc.php?id=BOE-A-2014-7065

77. Documento de Cons enso sobre profilaxis postexposición ocupacion al y no ocupacional en relación con el VH, VHB y VHC en adul tos y niños. Enferm Infecc Microbiol Clin. 2016;34(2):121.e1-121.e15.

78. Instituto Nacional de Estadística. Población extra njera por nacionalidad y sexo. Estadística del Padrón Continuo. $2019 . \quad$ Disponible en: https://www.ine.es/jaxi/Tabla.htm?path=/t20/e245/p04/provi/l0/\&file=0ccaa002.px

79. CADTH. Screening for Hepa titis C Virus: A Sys tema tic Review. Ottawa (ON): Canadian Agency for Drugs and Technologies in Health; 2017. (CADTH Health Technology Assessments). Disponible en: https://www.cadth.ca/dv/screening-hepatitis-c-virus-systematic-review

80. Chou R, Cottrell E, Wasson N, Ra hman B, Guise J, Oregon Evidence-based Practice Center under Contract No. 290-2007-10057-I.). Screening for hepati tis C virus infection in a dults: U.S. Comparative Effectiveness Review No. 69. Rockville, MD: Agency for Healthcare Research and Quality; 2012 p. 349-57. Disponible en: www.effectivehealthcare.ahrq.gov/reports/final.cfm.

81. Jordan A, Perlman D. The Shift in Emphasis From Risk-Based to Age-Based Hepatitis C Virus (HCV) Testing in the US Tends to Remove Injection Drug Use From Discourse on HCV. Subst Use Misuse. 2017;52(3):340-50.

82. Aguilera Guirao A, Alonso Fernández R, Córdoba Cortijo J, Fuertes Ortiz de Urbina A. Diagnóstico microbiológico de las hepatitis víricas. 50. En: Cercenado Mansilla E, Cantón Moreno R, editores. Procedimientos en Microbiología Clínica. Sociedad Española de Enfermedades Infecciosas y Microbiología Clínica $\quad 2014.2$ Disponible $\quad$ en: https://seimc.org/contenidos/documentoscientificos/procedimientosmicrobiologia/seimcprocedimientomicrobiologia50.pdf

83. Aguilera A, Al a dos JC, Al onso R, Eiros JM, García F. Posición actual de la carga viral frente a la determinación de antígeno core del virus de la hepatitis C. Enferm I nfecc Microbiol Clin. 2020;38(Supl 1):12-8.

84. SEIMC, SEPD, GEHEP, AEEH, AEHVE. Consenso para el diagnóstico de la infección activa por VHC en un único paso. 2018. Disponible en: http://a ehve.org/consenso-para-el-diagnostico-de-la-infeccion-activa-por-vhc-enun-unico-paso/

85. European Association for the Study of the Liver. EASL Recommendations on Trea tment of Hepatitis C 2018. J Hepa tol. 2018;69(2):461-511.

86. Arribas García J. Valoración del antígeno del core como alternativa en el cribado rutinario y de urgencia del virus de la hepatitis C. Universidad de Zaragoza; 2017. Disponible en: https://zaguan.unizar.es/record/59990/files/TESIS-2017-011.pdf

87. Tillmann $\mathrm{H}$. Hepatitis $\mathrm{C}$ virus core antigen tes ting: Rol e in diagnosis, disease monitoring and treatment. World J Gastroenterol. 2014;20(22):6701-6.

88. Feld JJ. Hepatitis C Vi rus Diagnostics: The Road to Simplification. Clin Liver Dis (Hoboken). 2018;12(5):125-9.

89. World Hepatitis Alliance. Find the missing millions. 2019. Disponible en: https://www.worldhepatitisalliance.org/missing-millions/wp-content/uploads/2019/07/WHOprequalification-list-.pdf

90. Treatment Action Group. Pipeline Report. HCV Diagnostics. 2019. Disponible en: https://www.treatmentactiongroup.org/wp-content/uploads/2011/08/pipeline_hcv_diagnostics_2019.pdf 
91. Saludes V, Antuori A, Folch C, González N, Ibáñez N, MajóX, et al. Uti lity of a one-step screening a nd diagnosis strategy for viremic HCV infection among people who inject drugs in Catalonia. Int J Drug Policy. 2019;74:23645.

92. Real Decreto $1662 / 2000$, de 29 de septiembre, sobre productos sanitarios para diagnóstico «in vitro». BOE 30/09/2000, núm. 235.

93. Laza rus JV, Pericàs JM, Picchio C, Cernosa J, Hoekstra M, Luhmann N, et al. We know DAAs work, so now what?: Simpl ifying models of ca re to enhance the hepatitis C cascade. Journal of I nternal Medicine. 2019;286(5):50325.

94. Ministerio de Sanidad. Equidad en salud y Desigualdades sociales en salud. Disponible en: https://www.mscbs.gob.es/profesionales/saludPublica/prevPromocion/promocion/desigualdadSalud/Equid adSaludyDSS.htm

95. Ajunta ment de Terrassa. Guía para incorporar la interseccionalidad en las políticas locales. 2019. Disponible en: http://igualtatsconnect.cat/wp-content/uploads/2019/06/Publicacion-Igualtats-Connect-ES.pdf

96. Beijer U, WolfA, Fazel S. Prevalence of tuberculosis, hepatitis C virus, and HIV in homeless people: a systematic review and meta-analysis. Lancet Infect Dis. 2012;12(11):859-70.

97. Ros Collado M, Ollé Rodríguez C. Acceso y utilización de los servicios de salud: atención al paciente inmigrante. Dificultades y posibles soluciones. En: La prevención de la infección del VIH/SIDA en la población inmigrante. Madrid: Ministerio de Sanidad y Consumo; Disponible en: https://www.mscbs.gob.es/ciudadanos/enfLesiones/enfTransmisibles/sida/prevencion/inmigrantes/docs/pr evencionVIH_SIDAPoblacionInmigrante06.pdf

98. Juanmarti Mes tres A, López Casasnovas G, Vall Castelló J. The deadly effects of losing health insurance. CRESUPF Working Paper \#201802-104. 2018; Disponible en: https ://ep00.epimg.net/descargables/2018/04/13/617bc3f9263d9a0dbcf3704f8d75a095.pdf

99. Ministerio de Sanidad, Servicios Sociales e I gualdad. Estrategia Nacional Integral para Personas sin Hogar 20152020. Madrid; 2015.2 Disponible en: https://www.mscbs.gob.es/ssi/familiasInfancia/ServiciosSociales/docs/EstrategiaPSH20152020.pdf

100. European As sociation for the Study of the Liver. EASL position sta tement on I iver disease and migrant health. 2018. Disponible en: https://easl.eu/wp-content/uploads/2019/04/EASL-Position-Statement-on-LiverDis ease-and-Migrant-Health.pdf

101. Sperle I, Hedrich D, PalczakK, Si ngleton N, European Monitoring Centre for Drugs a nd Drug Addictioin, Robert Kock Institut. Barriers to HCV Testing in Drug Treatment Services for People who Inject Drugs. 7th International Symposium on Hepatitis Care in Drug Users; 2018 sep 19; Cascais, Portugal. Disponible en: http://www.emcdda.europa.eu/system/files/publications/11481/poster-barriers-to-hcv-testing.pdf

102. Fundación Atenea. Hombres, Mujeres y Drogodependencias Explicación social de las diferencias de género en el consumo problemático de drogas. 2016. Disponible en: http://funda cionatenea.org/http://fundacionatenea.org/wp-content/uploads/2017/02/Hombres-mujeres-ydrogodependencias.pdf

103. Delegación del Gobierno para el Plan Nacional sobre Drogas. Estrategia Nacional sobre Drogas 2009-2016. Informe de la evaluación final. Ministerio de Sanidad, Servicios Social es e Igualdad; 2017. Disponible en: http://www.pnsd.mscbs.gob.es/pnsd/estrategiaNacional/docs/2017_Informe_Evaluacion_Final_Estrategia_ Nacional_sobre_Drogas_2009_2016.pdf

104. Crespo J, García-Samaniego J, Aguilera A, Calleja J, Eiros J, Blasco A, et al. Diagnóstico en un solo paso de la hepatitis C en 2019: una realidad en España. Gastroenterol Hepatol. 45(Espec Congr 1):89-90.

105. Casas P, et al. Towards the elimination of hepatitis C: Implementation of reflex testing in Andalusia. Rev Esp Enferm Dig. 2020;(aceptado para publicación, en prensa).

106. Dirección General de Salud Pública. La Hepatitis C. Cons ejería de Sanidad, Comunidad de Madrid; 2019. Disponible en: http://www.madrid.org/bvirtual/BVCM020274.pdf

107. Plan para la eliminación de la hepatitis C en Aragón. Dirección General de Asistencia Sanitaria, Gobierno de Aragón; 2019.2 Disponible en: https://www.aragon.es/documents/20127/3827794/PLAN+ESTRAT\%C3\%89GICO+PARA+LA+ELIMINACI\%C3 $\% 93 \mathrm{~N}+\mathrm{DE}+\mathrm{LA}+\mathrm{HEPATITIS}+\mathrm{C}+\mathrm{EN}+\mathrm{ARAG} \%$ C3\%93N.pdf/6fa98ceb-b31e-db5e-0e5bOb6e21ac59e1?t=1562230046536 
108. Gómez i Prat J, Ouaarab H, Saludes V, González-Gómez S, Antuori A, Buti M, et al. Hepatitis C micro-elimination pilot strategy in Pakistani migrants in Cata lonia through the implementation of a community intervention: interim results of the HepC-linkstudy. PosterTHU407. The International Liver Congress (ILC 2020); 2020 ago 25; Londres.

109. Sánchez Antolín, G, Sañudo S, Jiménez T, Blanco Ledo AM, Martín Sobrino N, García Vela JM. Hepatitis C. un ejemplo de planificación estratégica des de un área sanitaria. En: XXI Congreso Nacional de Hos pitales y Gestión Sanitaria. Santiago de Compostela, 8-10 de mayo, 2019.

110. Gobierno de Navarra. El $81,7 \%$ de los pacientes diagnosticados de Hepatitis C han superadola infección, y un $3 \%$ adicional ya ha iniciado el tratamiento. 2019. Disponible en: https://www.navarra.es/es/noticias/2019/07/27/el-81-7-de-los-pacientes-diagnosticados-de-hepatitis-chan-superado-la-infeccion-y-un-3-adicional-ya-ha-iniciado-el-tratamiento

111. HepCare Europe. UCD School of Medicine. Disponible en: http://www.ucd.ie/medicine/hepcare/

112. Macías J, Fernández-Fuertes M, Rincón P, Corma A, Merchante N, Gómez-Mateos J, et al. Barreras para la eliminación de la infección por VHC en us uarios de drogas y otros colectivos con riesgo de exclusión social: proyecto HepCare Europe Spain. Enferm Infecc Microbiol Clin. 2019;37(Espec Cong 2):1.

113. Lens S, Miralpeix A, Gálvez M, MartróE, González N, Rodríguez-Tajes S, et al. Modelo externalizado de cribado y acceso al tratamiento de la hepatitis $C$ en el mayor centro de reducción de daños del área de Barcelona. Gastroenterol Hepatol. 2020;43(Espec Congr 1):95.

114. Egea Zapata C, Carvajal Pérez L, Gómez Sánchez R, Sei quer de la Peña C, Martínez Sánchez R, Aguilar M, et al. Segui mi ento del VHC en usuarios de drogas en tera pias sustitutivas de opiáceos. Nuevas estrategias. Enferm Infecc Microbiol Clin. 2019;37(Espec Cong 2):8.

115. Saludes V, Antuori A, La za rus JV, Fol ch C, González-Gómez S, González N, et al. Evaluation of the Xpert HCV VL Fingers tick point-of-care assay and dried blood spot HCV-RNA tes ting as simplified diagnostic strategies among people who inject drugs in Catalonia, Spain. International Journal of Drug Policy. 2020;80:102734.

116. Fuentes López A, Salazar González A, García García F, Ruiz M, Ruiz Maldonado M, Valencia J, et al. Cascada de tratamiento de la hepatitis $C$ en un centro de adicciones. Enferm Infecc Microbiol Clin. 2019;37(Espec Cong 2):11.

117. Cuadrado A, Llerena S, Cobo C, Pallás JR, Mateo M, Cabezas J, et al. Microenvironment Eradication of Hepatitis C: A Novel Treatment Paradigm. Am J Gastroenterol. 2018;113(11):1639-48. 